\title{
Drug-Drug Interactions at Organic Cation Transporter 1
}

\author{
Shiwei Zhou ${ }^{1,2,3}$, Sujuan Zeng ${ }^{1}$ and Yan Shu ${ }^{1,2 *}$ \\ ${ }^{1}$ Key Laboratory of Oral Medicine, School and Hospital of Stomatology, Guangzhou Medical University, Guangzhou, China, \\ ${ }^{2}$ Department of Pharmaceutical Sciences, School of Pharmacy, University of Maryland at Baltimore, Baltimore, MD, \\ United States, ${ }^{3}$ Department of Thyroid Surgery, The Second Xiangya Hospital, Central South University, Hunan, China
}

The interaction between drugs and various transporters is one of the decisive factors that affect the pharmacokinetics and pharmacodynamics of drugs. The organic cation transporter 1 (OCT1) is a member of the Solute Carrier 22A (SLC22A) family that plays a vital role in the membrane transport of organic cations including endogenous substances and xenobiotics. This article mainly discusses the drug-drug interactions (DDIs) mediated by OCT1 and their clinical significance.

Keywords: organic cation transporters, OCT1, substrate, inhibitor, drug-drug interaction

\section{INTRODUCTION}

OPEN ACCESS

Edited by:

Shuiying $\mathrm{Hu}$,

The Ohio State University,

United States

Reviewed by:

Bruno Hagenbuch,

University of Kansas Medical Center,

United States

Yurong Lai,

Gilead, United States

*Correspondence:

Yan Shu

yshu@rx.umaryland.edu

Specialty section: This article was submitted to Drug Metabolism and Transport, a section of the journal

Frontiers in Pharmacology

Received: 12 November 2020

Accepted: 13 January 2021

Published: 17 February 2021

Citation:

Zhou S, Zeng S and Shu Y (2021) Drug-Drug Interactions at Organic

Cation Transporter 1.

Front. Pharmacol. 12:628705.

doi: 10.3389/fphar.2021.628705
Drug-drug interactions (DDIs) are among the critical factors in determining clinical drug disposition and response. DDIs refer to the changes in toxicity, pharmacokinetics or pharmacodynamics of a drug when two or more drugs are applied simultaneously or sequentially (Palleria et al., 2013; Prueksaritanont et al., 2013; Koepsell, 2015). DDIs on one hand can enhance the efficacy of a drug and on the other hand may reduce the efficacy or even lead to toxic reactions to a drug (Palleria et al., 2013; Sun et al., 2016; Niu et al., 2019). Movement of endogenous and exogenous chemicals across the biological membrane is usually mediated by transporter proteins that play a central role in the physiological function, pharmacological action, and elimination fate of these compounds. Drug transporters usually have extensive binding affinity toward a broad spectrum of small molecule substrates and inhibitors, suggesting their important role in DDIs (Girardin, 2006; Koepsell, 2015; Liang et al., 2015). Nowadays, more and more attention has been paid to the DDIs mediated by drug transporters. Transporter-mediated DDIs affect pharmacokinetics and pharmacodynamics, especially drug absorption and elimination (Giacomini et al., 2010; Liu et al., 2015). Drug transporters exist in almost all organs of human body, mainly in the brain, intestinal tract, kidney, liver, and lung (Liu and Pan, 2019).

The human organic cation transporter 1 (hOCT1), encoded by the SLC22A1 gene, is highly expressed in the liver and possesses a broad substrate specificity (Koepsell et al., 2003). Approximately $40 \%$ of prescription medicines are organic cations (Neuhoff et al., 2003; Koepsell, 2020). The disposition of more than 120 drugs has been related to the activity of OCTs including OCT1-3 (Nies and Schwab, 2010). OCT1 function is thus closely related to pharmacotherapy of various diseases including cancer, cardiovascular and cerebrovascular diseases, digestive system diseases, substance addiction and CNS diseases. Because OCT1 can also transport certain endogenous metabolites, its activity may also be of great significance to the maintenance of homeostasis in the body (Nies et al., 2011b; Lozano et al., 2013; Brosseau and Ramotar, 2019; Li et al., 2019). Herein the physiological and pharmacological effects of OCT1 are briefly introduced, followed by a focused review on DDIs mediated by OCT1. 


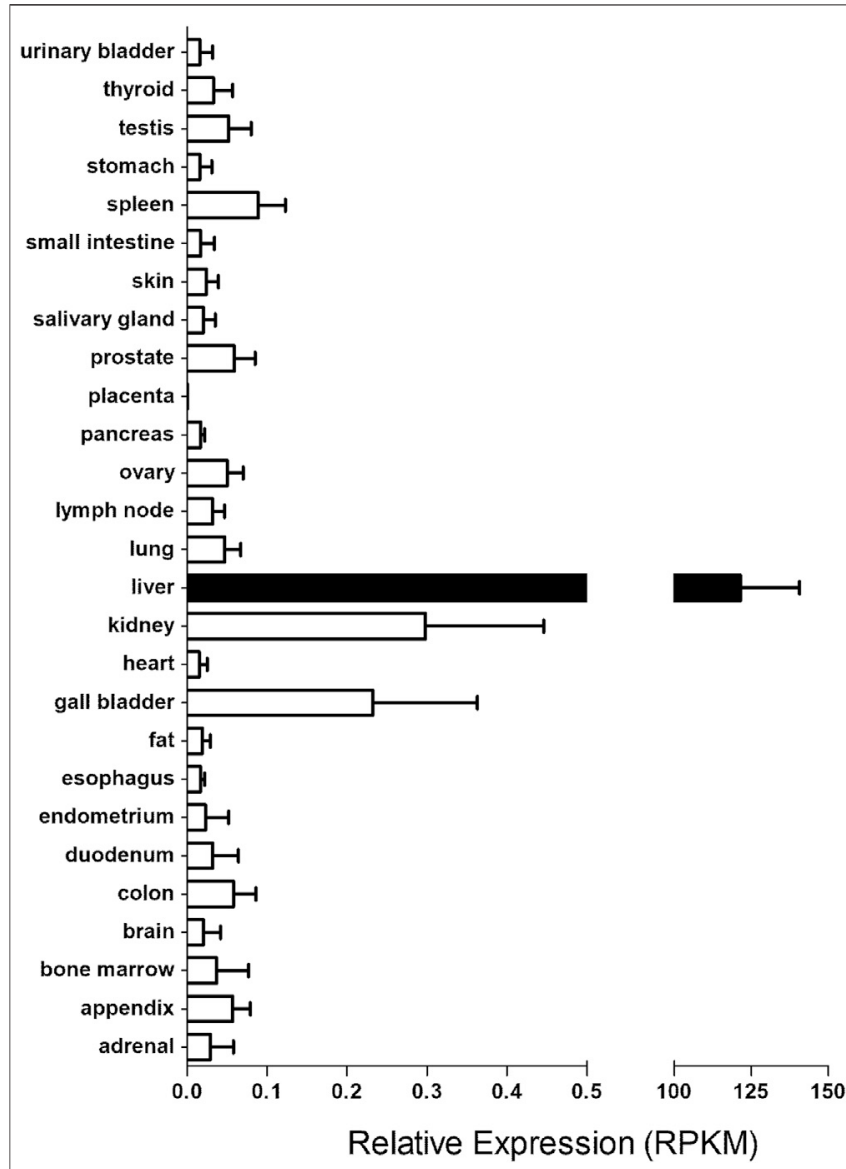

FIGURE 1 | The transcript levels of SLC22A1 gene in major human tissues. The RNA sequencing data for human tissues were retrieved from https://www.ncbi.nlm.nih.gov/gene/6580. RPKM stands for the Reads Per kilobase of transcript, per Million mapped reads in RNA sequencing, which is a normalized unit of transcript expression.

\section{MOLECULAR CLONING AND CHARACTERIZATION OF ORGANIC CATION TRANSPORTER 1}

OCT1 is a member of the Solute Carrier (SLC) Family 22 responsible for the uptake of numerous organic cations, anions and zwitterions, across the plasma membrane (Koepsell, 2013). Rat OCT1 (rOCT1) was the first cloned member of the SLC22A family. rOCT1 was cloned in 1994, and hOCT1 in 1997 by Koepsell group (Grundemann et al., 1994; Gorboulev et al., 1997). The human SLC22A1 gene encoding hOCT1 is located on chromosome 6q26 and consists of 11 exons and 10 introns (Koehler et al., 1997). The human OCT1 protein has 554 amino acids. Like most transporters in the SLC22A family, it is composed of 12 a-helical transmembrane domains (TMDs) with intracellular N- and C-termini (Shu et al., 2003; Koepsell, 2013; Lozano et al., 2013). There is a large glycosylated extracellular loop between the TMD 1 and TMD 2, which can form disulfide bonds for protein oligomerization. In addition, between the TMD 6 and TMD 7, there is an intracellular loop with consensus sites that can be phosphorylated by several protein kinases. These glycosylation and phosphorylation sites are associated with the regulation of transport functions by regulatory proteins such as protein kinases A\&C (Ciarimboli and Schlatter, 2005; Shu, 2011; Brosseau and Ramotar, 2019).

\section{DISTRIBUTION AND FUNCTION OF ORGANIC CATION TRANSPORTER 1 IN HUMAN TISSUES}

The importance of hOCT1 in drug disposition and response is implicated by its tissue expression pattern and cellular location. Although hOCT1 is widely distributed in human tissues, it is primarily expressed in the liver (Koepsell et al., 2003) (Figure 1). In hepatocytes, it has been located at the sinusoidal (basolateral) membrane. Of note, it is less expressed in cholangiocytes as compared to hepatocytes in the liver (Nies et al., 2009). In the intestine, there is evidence from immunolocalization and pharmacokinetics (PK) studies in support of hOCT1 expression in the basolateral membrane (Muller et al., 2005). However, this has been challenged by other results which supported that hOCT1 and mouse OCT1 (mOCT1) were actually expressed in the apical membrane of intestinal epithelia cells (Han et al., 2013). Further investigation is needed to settle this dispute. In the kidney, while rOCT1 has been reported to be located to the basolateral membrane of epithelial cells in the proximal tubules (Karbach et al., 2000; Sugawara-Yokoo et al., 2000), there is immunohistochemistry evidence supporting the location of hOCT1 in the apical membranes of proximal and distal tubules (Tzvetkov et al., 2009). In the lung, OCT1 is located in the lumen (apical) membrane of ciliated cells (Lips et al., 2005) and bronchial epithelial cells (Mukherjee et al., 2012). In addition, OCT1 has been reported to be expressed on the luminal side of brain microvessel endothelial cells (BMECs) (Lin et al., 2010), olfactory and nasal respiratory tissues (Chemuturi and Donovan, 2007), ovary, prostate, testis (Jung et al., 2008), cardiomyocytes (Rossato et al., 2011) and $\mathrm{CD}^{+}$cells of HIVinfected patients (Minuesa et al., 2008; Jung et al., 2013).

OCT1 is a poly-specific amphiphilic solute facilitator of transmembrane protein which bidirectionally mediates the transport of electrogenic organic cations across the plasma membrane in a manner independent of either $\mathrm{Na}^{+}$or $\mathrm{Ca}^{2+}$ gradients (Busch et al., 1996; Gorboulev et al., 1997; Brosseau and Ramotar, 2019). OCT1 not only mediates the delivery of many cationic drugs and endogenous substrates into hepatocytes from the hepatic sinuses but also the release of organic cations from hepatocytes into the hepatic sinuses (Jonker and Schinkel, 2004; Koepsell et al., 2007; Nies et al., 2009). Consistent with its tissue expression patterns, OCT1 is also involved in the transport of certain substances in other organs. For example, it can regulate the secretion and absorption of organic cations in the small intestine (Koepsell, 1998), the reabsorption of ultrafiltration cations in the kidney (Koepsell et al., 1999), and the absorption of some drugs in the lung (Lips et al., 2005). Furthermore, OCT1 has been reported to promote organic 
TABLE 1 | List of substrates and inhibitors of OCT1. The related information is cited from Drugbank https://www.drugbank.ca/categories/DBCAT004550, https://www. drugbank.ca/categories/DBCAT004549 and the references of this review.

\section{Drug category \\ Substrates}

Alkaloids

Alpha-2A adrenergic receptor agonists

Alpha-blockers

Anesthetics

Antiarrhythic drugs

Antibiotics

Anticancer drugs

Anticoagulant drugs

Anticonvulsant drugs

Antidepressant drugs

Antifungal drugs

Antihistamine agents

Antihypertensive drugs

Antimalarial drugs

Antimuscarinic drugs

Antiparasitic drugs

Antiparkinson drugs

Antiplatelet drugs

Antiprotozoal drugs

Antipsychotic drugs

Antituberculosis drugs

Antitussive drugs

Antiviral drugs

Beta-2 adrenergic agonist

Nonselective beta adrenergic

receptor blocker

Bronchodilators

Diuretics

Endogenous compounds

Experimental compounds

Flavonoids

Histamine $\mathrm{H} 3$ receptor

antagonists

Hormone drugs

\section{Hypoglycemic drugs}

$\mathrm{H} 2$ receptor antagonists

Immunosuppressants

Janus kinase inhibitors (JAK

inhibitors)

Muscarinic antagonists

Neuromuscular blockers

Opioids

Selective serotonin receptor agonists

Serotonin 5-HT3 receptor antagonists

Inhibitors

Coptisine, jatrorrhizine, epiberberine and berberrubine, nitidine chloride, monocrotaline, retrorsine

Uanfacine

Prazosin

Verapamil

Amoxicillin

Cytarabine, nintedanib, oxaliplatin, picoplatin

Nafamostat

Lamotrigine

Fluoxetine

Chlorpheniramine maleate, diphenhydramine Amiloride

Quinine, proguanil

Pramipexole, amantadine

Pentamidine, furamidine

Sulpiride, amisulpride, haloperidol

Ethambutol, isoniazid, prothionamide, para-aminosalicylic acid

Ganciclovir, acyclovir, amantadine, lamivudine, peramivir

Fenoterol, formoterol, salmeterol

Nadolol

Ipratropium, salbutamol

Histamine, dopamine, choline, epinephrine, norepinephrine, spermine, spermidine, serotonin, noradrenaline

Acetylcholine, choline salicylate, rhodamine, tropane alkaloids, cycloguanil, 4-(4-(dimethylamino)styryl)-N-methylpyridinium, synephrine

Quercetin

Metformin, phenformin, buformin

Cimetidine, ranitidine, famotidine

Trospium chloride, oxybutynin

Pancuronium, tubocurarine, rocuronium

Methylnaltrexone, morphine, hydromorphone, norlevorphanol, norfentanyl, noroxycodone, meptazinol, 3-methoxymorphinan, oxymorphone, dextrorphan

\section{Sumatriptan}

Ondansetron, tropisetron
Nuciferine, berberine, retrorsine, anisodine, monocrotaline

Guanfacine

Prazosin, phenoxybenzamine

Cocaine, lidocaine

Procainamide, verapamil, disopyramide, quinidine, dronedarone, propafenone

Levofloxacin, trimethoprim, moxifloxacin

Rucaparib, dacomitinib, gilteritinib, palbociclib, nintedanib, irinotecan, erlotinib, nilotinib, dasatinib, mitoxantrone, paclitaxel, tamoxifen, amsacrine

Lamotrigine

Desipramine, fluoxetine, imipramine, amitriptyline, trimipramine, citalopram, fluvoxamine, maprotiline, nomifensine, paroxetine, reboxetine, nefazodone, imipramine

Ketoconazole, itraconazole, clotrimazole, isavuconazole, griseofulvin

Chlorpheniramine, dexchlorpheniramine maleate, diphenhydramine Reserpine, doxazosin, amiloride, diltiazem, clonidine

Quinine

Atropine

Pyrimethamine

Amantadine

Clopidogrel

Pentamidine, furamidine, eflornithine

Quetiapine, chlorpromazine, clozapine, levomepromazine,

remoxipride

Pyrazinamide

Carbetapentane

Ganciclovir, acyclovir, saquinavir, nelfinavir, indinavir, ritonavir, darunavir, efavirenz, nevirapine, daclatasvir

Formoterol, salmeterol

Carvedilol, bucindolol

Ipratropium, metaproterenol, salbutamol

Spironolactone

Prostaglandin, choline, guanidine

Nicotine, choline salicylate, tropane alkaloids, N1-

methylnicotinamide, creatinine, corticosterone

Pitolisant

Progesterone, estradiol acetate, estradiol benzoate, estradio cypionate, estradiol dienanthate, estradiol valerate, osilodrostat Phenformin, linagliptin, repaglinide, rosiglitazone, sitagliptin Cimetidine, ranitidine, famotidine

Cyclosporine

Peficitinib

Oxybutynin

Pancuronium, tubocurarine, rocuronium

Dextromethorphan, dextrorphan, levorphanol, levomethorphan, dextromethorphan, meptazinol, sufentanil, tapentadol, pethidine, norlevorphanol, tilidine, fentanyl, N-desmethyltramadol, morphine, nortilidine, tramadol

Ondansetron 
TABLE 1 | (Continued) List of substrates and inhibitors of OCT1. The related information is cited from Drugbank https://www.drugbank.ca/categories/DBCATO04550, https://www.drugbank.ca/categories/DBCAT004549 and the references of this review.

\begin{tabular}{lcc}
\hline Drug category & Substrates & Inhibitors \\
\hline $\begin{array}{l}\text { Uricosuric drugs } \\
\text { Vitamins }\end{array}$ & Thiamine & Probenecid \\
Serotonin $(5-\mathrm{HT}) 1 \mathrm{~F}$ receptor & & Lasmiditan \\
agonists & &
\end{tabular}

cation crossing of the blood-brain barrier (BBB) (Lin et al., 2010), mediate the uptake of endogenous substrates into olfactory and respiratory mucosae (Chemuturi and Donovan, 2007) and the antiviral drugs into human immune cells (Minuesa et al., 2008; Jung et al., 2013).

\section{ALTERATION OF ORGANIC CATION TRANSPORTER 1 BY LIVER DISEASES}

The liver predominantly expresses OCT1 and is the major organ responsible for drug metabolism in human body (Nishimura and Naito, 2005). A growing body of evidence suggests that the expression and function of OCT1 changes in liver diseases, which could affect drug disposition in the body, not only by increasing the possibility of DDIs but also by enhancing the complexity of drug treatment (Schaeffeler et al., 2011; Lautem et al., 2013; Li et al., 2019). Compared to that in normal rat liver tissues, rOCT1 mRNA expression was decreased in the presence of cholestasis (Cherrington et al., 2004). Interestingly, in the early stage of liver fibrosis associated with hepatitis $\mathrm{C}$ virus (HCV) infection, the hOCT1 mRNA expression was significantly increased (Ogasawara et al., 2010); however it decreases during the aggravation of fibrosis (Hanada et al., 2012). In addition, the alteration in human OCT1 expression in miscellaneous tumor cells, such as hepatocellular carcinoma (HCC) cells and cholangiocellular carcinoma (CGC), has also been reported. Compared with adjacent normal liver tissue, the expression of OCT1 was significantly down-regulated in primary liver cancers originating from epithelial cells such as HCC, CGC, and hepatoblastoma (Herraez et al., 2013; Lautem et al., 2013; Namisaki et al., 2014). In HCC and CGC, the reduced expression of OCT1 was associated with advanced tumor stages and poor patient survival (Heise et al., 2012; Lautem et al., 2013). The decreased expression appears to be caused by DNA methylation in the promoter of the SLC22A1 gene (Schaeffeler et al., 2011).

\section{ORGANIC CATION TRANSPORTER 1 SUBSTRATES AND INHIBITORS}

OCT1 works to regulate the cellular uptake of substrates. The substrates of OCT1 are usually organic cations with one or two positive charges, or weak bases with positive charges at physiological pH (Koepsell et al., 2003). Some uncharged compounds such as cimetidine can also be transported under alkaline conditions. The molecular weight of non-substrate inhibitors for OCT1 is in general larger than those of substrates. Sometimes, multiple inhibitor molecules can bind to the transporter protein simultaneously (Koepsell et al., 2003; Nies et al., 2011b; Shu, 2011; Koepsell, 2020). Most, if not all, of the substrates and inhibitors of OCT1 reported in the literature are summarized in Table $\mathbf{1 .}$

\section{INTERACTION OF ORGANIC CATION TRANSPORTER 1 WITH CLINICAL MEDICATION (FIGURE 2)}

Many drugs are present as cations at physiological $\mathrm{pH}$. As the most abundant organic cation transporter in the human liver, OCT1 mediates the transport of many organic cationic drugs across the hepatocyte membrane and may play an important role in regulation of metabolism of many drugs (Koepsell et al., 2007; Shu, 2011). Two or more therapeutic drugs that are OCT1 substrates may be administered simultaneously or subsequently in clinical applications. Because the expression level of OCT1 is relatively constant, competition between these substrates can happen for their cellular transport via OCT1. Likewise, some endogenous substrates can also compete for the uptake of xenobiotic drug substrates (Brosseau and Ramotar, 2019). In addition to the competitive inhibition of one substrate by another, many compounds such as lidocaine, prazosin, cocaine and dasatinib, which are not substrates of OCT1, can inhibit the uptake of OCT1 substrates (Brosseau and Ramotar, 2019). The inhibitors of OCT1, like those of other transporter proteins, are generally classified as competitive and non-competitive, depending on how the compounds interact with the binding site at the transporter protein and subsequently the dissociation manner (Belzer et al., 2013; Chen E. C. et al., 2017; Boxberger et al., 2018). However, both competitive and non-competitive inhibition may result in DDIs of clinical significance.

There is abundant evidence supporting a role of OCT1 in DDIs pre-clinically; however, only a few DDIs between OCT1 inhibitors/substrates have been reported in human subjects. Notably, even for these clinical DDIs, a contribution from other transporters or mechanism may not be excluded. For example, metformin is the victim drug in all of these clinical DDIs (Table 2). However, metformin is a substrate not only for OCT1 but also for OCT2, OCT3, plasma membrane monoamine transporter (PMAT), serotonin reuptake transporter (SERT), and others (Graham et al., 2011; Gong et al., 2012). In particular, 


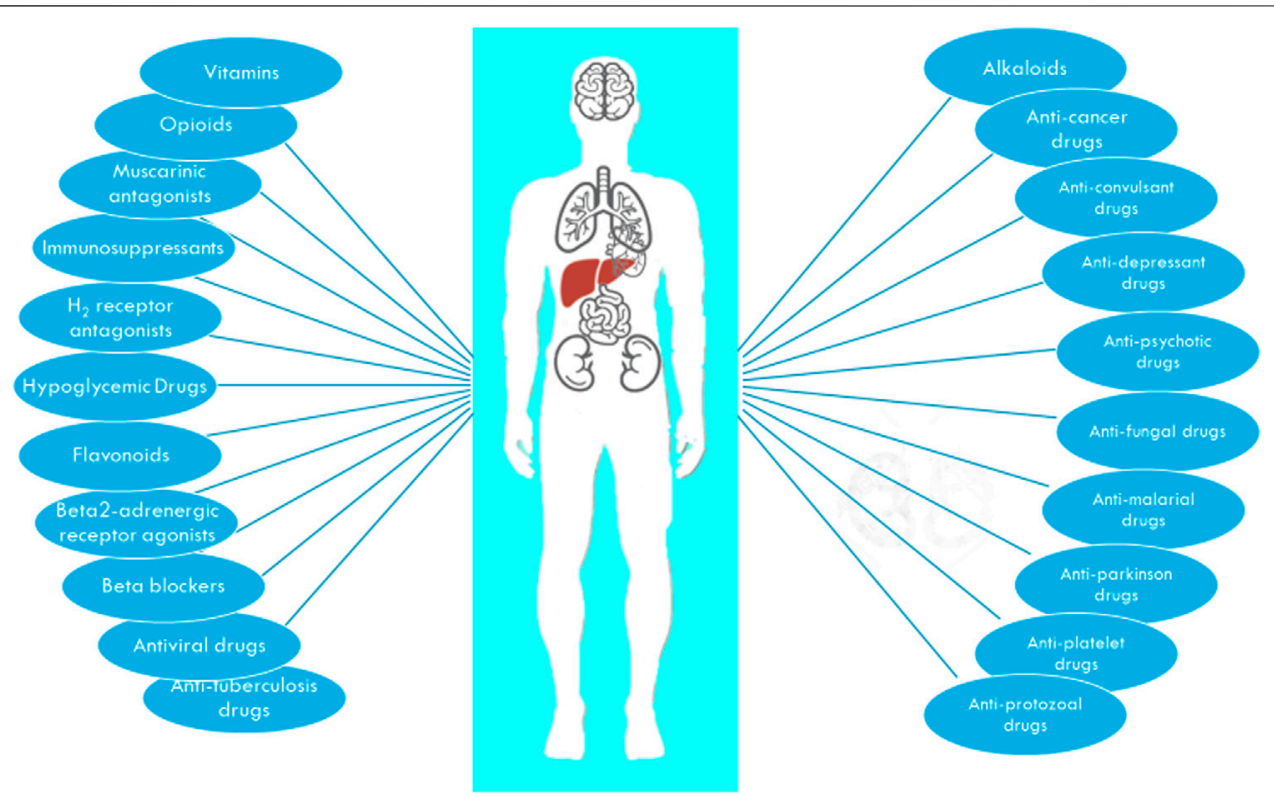

FIGURE 2 | The major drug classes interacting with OCT1.

TABLE 2 | Clinically relevant DDls between OCT1 substrates/inhibitors with metformin. Note: Although OCT1 is assumed to play a role in these DDls, the contribution from other transporters or mechanism cannot be ruled out.

\begin{tabular}{|c|c|c|}
\hline Perpetrator drug & Victim drug & Effects \\
\hline Daclatasvir & Metformin & $\begin{array}{l}\text { The number of adverse events increased in subjects that received both daclatasvir and metformin as compared to those } \\
\text { receiving metformin alone Smolders et al. (2017) }\end{array}$ \\
\hline Opioids & Metformin & $\begin{array}{l}\text { Opioids reduced the effect of metformin on the abundance of gut bifidobacterium, which is likely due to OCT1 inhibition by } \\
\text { opioids Barengolts et al. (2018) }\end{array}$ \\
\hline Sitagliptin & Metformin & $\begin{array}{l}\text { In subjects who did not reach the maximal goal of } \mathrm{HbA} 1 \mathrm{c} \text { with a sub-maximal dose of metformin, the addition of sitagliptin } \\
\text { improved the glycemic response and glycated hemoglobin goals for metformin treatment Frias et al. (2019) }\end{array}$ \\
\hline Rifampin & Metformin & $\begin{array}{l}\text { Rifampin can up-regulate the expression of OCT1 in peripheral blood cells, increase the concentration of metformin in the } \\
\text { blood and enhance the hypoglycemic effect of metformin Cho et al. (2011) }\end{array}$ \\
\hline OCT1 inhibitors & Metformin & $\begin{array}{l}\text { Concomitant use of medications, known to inhibit OCT1 activity, was associated with gastrointestinal side effects and } \\
\text { intolerance of metformin Dujic et al. (2015) }\end{array}$ \\
\hline
\end{tabular}

OCT2 plays an important role in the renal elimination of metformin (Kimura et al., 2005). Although the role of OCT1 in metformin disposition and efficacy in human subjects is well supported by genetic evidence (Mofo Mato et al., 2018), the perpetrator drugs could have affected the activities of other metformin transporters, which might also contribute to the observed DDIs.

The International Transporter Consortium, in collaboration with US FDA, has issued recommendations on transporter function assessment during drug development (Giacomini et al., 2010; Zamek-Gliszczynski et al., 2012; Brouwer et al., 2013; Hillgren et al., 2013; Tweedie et al., 2013). However, although the assessment of OCT1 is suggested by the
European Medicines Agency (EMA), it has not been included in the industry guidance on DDI studies by FDA. According to the FDA guidance, an inhibitory $K_{i}$ value of more than one-tenth of $\mathrm{C}_{\max }$ has been suggested for the perpetrator drug to cause a clinically relevant interaction with another victim drug that is transported by the same transporter. It is expected that many drugs may significantly inhibit the activity of OCT1 at their clinical plasma concentrations. Specific DDIs mediated by OCT1 for major classes of drugs are reviewed below. Notably, the majority of these DDIs are either speculated from cellular findings or only evident at the preclinical level of animal studies. Therefore, additional clinical studies are highly needed to ascertain the role of OCT1 in various DDIs. 


\subsection{Alkaloids}

Protoberberine alkaloids belong to isoquinoline alkaloids and are mainly found in the plants of Fumariaceae, Berberidaceae and Papaveraceae families, which include berberrubine, coptisine, jatrorrhizine, palmatine, epiberberine and corydaline. Proberberine alkaloids have been reported to possess a potent inhibitory effect on human OCT1/2/3 (Li et al., 2016). Moreover, coptisine, jatrorrhizine, epiberberine were found to be highaffinity substrates of OCTs, while berberrubine was a selective substrate for human OCT1 and OCT2, but not OCT3. The findings have provided useful information to understand the pharmacological effects of alkaloids or traditional herb medicines containing those alkaloids. In particular, the results suggest potential DDIs mediated by OCT1 between alkaloids and clinical used drugs.

Specifically, berberine, a quaternary ammonium alkaloid isolated from several plants, is the main effective component of rhizoma coptidis. Berberine has been reported to inhibit OCT1/2-mediated uptake of metformin in HEK293-OCT1 cells in a concentration dependent manner (Kwon et al., 2015). After intravenous administration of metformin with berberine, the initial blood concentration and Area Under Curve (AUC) of metformin were increased in rats, but the clearance rate and distribution volume of metformin were decreased. However, there was no change in the plasma concentration of berberine after administration with metformin. Shi et al. also reported a pharmacokinetic interaction between metformin and berberine (Shi et al., 2019). In their study, metformin and berberine were dosed by oral gavage. The plasma concentration and the AUC of metformin were decreased in rats that received berberine cotreatment compared to those that received metformin alone. Metformin was believed to be absorbed in the small intestine via OCT1 (Zhou et al., 2007; Graham et al., 2011; Han et al., 2015). rOCT1 inhibition by berberine may have contributed to the pharmacokinetic changes of oral metformin in rats.

Additional evidence suggests that the hepatic uptake of jatrorrhizine is mediated by a transport system belonging to the OATP and OCT families. In particular, prazosin, an OCT1 inhibitor, could potently inhibit OCT1-mediated uptake of jatrorrhizine in HEK-OCT1 cells. There are likely DDIs between the herbs containing jatrorrhizine and a substrate or inhibitor of OCT1 at the hepatobiliary disposition (Liang et al., 2020).

Nuciferine, one of the main active components of Nelumbo nucifera Gaertn, is considered as a promising agent for the treatment of obesity-related diseases. Li et al. characterized nuciferine as an inhibitor of OCT1 (Li et al., 2018). They found that nuciferine could reduce the concentration of metformin in the liver through mOct1 inhibition in mice. In addition, it could weaken the hypoglycemic effect of metformin. However, the effects of nuciferine on the hepatic concentration and hypoglycemic effect of metformin were present only for a period of time after nuciferine administration, suggesting that intermittent administration of nuciferine and metformin, if necessary, might prevent the DDI mediated by OCT1.

Nitidine chloride (NC) is a quaternary ammonium alkaloid with numerous pharmacological effects such as anticancer activity. However, NC also has hepatocellular toxicity. Li et al. reported that NC was a high affinity substrate of human OCT3 and OCT1 (Li et al., 2014b). The two transporters were believed to mediate the uptake of NC into hepatocytes and subsequently cause hepatotoxicity. Quinidine, an OCT1 inhibitor, could significantly reduce the hepatic uptake of NC and NC-induced toxicity in cultured primary rat hepatocytes. This study suggests OCT inhibition as a strategy to prevent clinical hepatotoxicity associated with NC use.

Monocrotaline (MCT) is a pyrrolizidine alkaloid and it has pneumotoxic and hepatotoxic effects in animals (Copple et al., 2002). Tu et al. demonstrated that MCT is a substrate and inhibitor of OCT1 and has a high affinity to the transporter (Tu et al., 2013). In MDCK-hOCT1 cells, OCT1 was found to play a vital role in the uptake and toxicity of MCT, and the inhibitor of OCT1, quinidine, could significantly inhibit the uptake of MCT, thereby reduce the MCT-induced toxicity.

\subsection{Anti-Cancer Drugs}

Oxaliplatin is an anti-cancer chemotherapeutic drug. Oxaliplatin has been characterized as an excellent substrate of human OCT1 and OCT2. The results by Zhang et al. have indicated that the cytotoxicity of oxaliplatin and its cellular accumulation could be inhibited by the OCT1 inhibitor disopyramide in MDCK-hOCT1 cells (Zhang et al., 2006). Furthermore, Buss et al. reported that pre- and co-incubation with atropine, an inhibitor of OCT1, significantly reduced oxaliplatin accumulation in drug-sensitive cells but not in drug-resistant cells (Buss et al., 2018). One possible mechanism is the alteration of transporter localization in the drug-resistant cells. The data suggest an association between OCT1 expression and oxaliplatin resistance.

Picoplatin is a third-generation platinum drug. It is very effective in the treatment of drug-resistant or refractory lung cancer. The chemical structures of picoplatin and oxaliplatin are similar. More et al. reported that the monoaqua complex of picoplatin (but not the diaqua complex) was a substrate of OCT1 (More et al., 2010). As similar for oxaliplatin in MDCK-hOCT1 cells, disopyramide reduced the cytotoxicity of picoplatin in lung cancer cell lines and the accumulation of platinum in HEKhOCT1 cells. These studies have provided a foundation to delineate the role of OCT transporters in platinum-based chemotherapy and the related toxicity.

Mitoxantrone is an anthraquinone drug which is used to treat prostate cancer and leukemia. It has been demonstrated as an inhibitor of OCT1 (Gupta et al., 2012). In addition, Li et al. have shown that mitoxantrone could reduce the apical (AP) to basolateral flux of peramivir in Caco-2 cells (Chen J. et al., 2017). The reason might be that mitoxantrone could inhibit the activity of OCT 1 which is expressed in the AP membrane of Caco-2 cells and plays a role in the influx of solutes in enterocytes. Thus, MCT administration may lead to a reduction in peramivir absorption.

Sorafenib, a multi-tyrosine kinase inhibitor (TKI), is considered as an effective targeting therapy for advanced liver cancer (Keating, 2017). OCT1 plays a role in the uptake of sorafenib into cells. The results by Al-Abdulla et al. indicated that sorafenib uptake was enhanced in the cells expressing 
hOCT1, which could be inhibited by the OCT inhibitor quinine (Al-Abdulla et al., 2019). Co-exposure with quinine suppressed not only hOCT1-mediated uptake of sorafenib but also sorafenibinduced cytotoxicity. In HCC patients treated with sorafenib, the protein expression of OCT1 at the plasma membrane was significantly associated with a beneficial response to sorafenib treatment. Interestingly, using the total healthy liver mRNA, there was no such association found (Geier et al., 2017). However, the relevance of OCT1 expression to sorafenib response remains controversial. Chen et al. recently reported that sorafenib was not a substrate of OCT1, and that the transporter was unlikely to participate in sorafenib disposition and influence its therapeutic effects in HCC (Chen et al., 2020).

Pazopanib is also a tyrosine kinase inhibitor. OCT1 has been reported to be responsible for the uptake of pazopanib in hepatocytes (Ellawatty et al., 2018). In addition, pazopanib is a potential inhibitor of OCT1 at clinically relevant concentrations. The unbound plasma concentration of pazopanib is slightly higher than the $\mathrm{IC}_{50}$ value of the pazopanib inhibiting OCT1mediated uptake of metformin, suggesting a clinically relevant interaction between pazopanib and other drugs mediated by OCT1.

There are additional TKIs that have been reported as OCT1 inhibitors. Minematsu et al. demonstrated that erlotinib and nilotinib were potent inhibitors of OCT1 at clinically relevant concentrations (Minematsu and Giacomini, 2011). The two drugs could significantly inhibit metformin uptake mediated by OCT1 in HEK-hOCT1 cells. At a concentration similar to the clinically achievable unbound plasma concentrations, the two TKIs could inhibit the uptake of oxaliplatin. These data implicate clinical DDIs between TKIs and other OCT1 substrates or inhibitors.

OCT1 also interacts with additional anti-cancer drugs. For example, rucaparib is a potent small-molecule inhibitor of poly(ADP-ribose) polymerase enzymes that are important in cancer development and metastasis (Colombo et al., 2018). The results by Liao et al. indicated that rucaparib could potently inhibit human OCT1/2-mediated metformin uptake in cells (Liao et al., 2020). Because inhibition of OCT1/2 could decrease the uptake of metformin in the liver and its elimination in the kidney, and might reduce its hepatic anti-hyperglycemic action, there is a possible undesirable interaction between rucaparib and metformin in diabetic cancer patients who are treated by these two drugs.

\subsection{Anti-Convulsant Drugs}

Lamotrigine, an anti-epileptic medication, is also used to delay mood episodes in adults with bipolar disorder. Dickens et al. have reported that lamotrigine is a substrate and inhibitor of OCT1 and its transport into human brain endothelial cells can be mediated via OCT1 (Dickens et al., 2012). In addition, the anti-psychotic quetiapine, an inhibitor of OCT1, could inhibit the uptake of lamotrigine in the hOCT1-transfected cells. Importantly, the in vitro $\mathrm{IC}_{50}$ value for the inhibition was slightly lower than the steady state $\mathrm{C}_{\max }$ in patients treated with quetiapine. Therefore, the concentration required to inhibit OCT1 in the patient is achievable after treatment with quetiapine. Although the effect of lamotrigine on cellular transport of quetiapine is uncertain, the potential DDI in patients between the two drugs should be considered.

\subsection{Anti-Depressant and Anti-Psychotic Drugs}

The $\mathrm{BBB}$ is an important physiological barrier between the central nervous system and the blood circulation. The antidepressants and antipsychotics must cross the BBB into the central nervous system to function. OCT transporters have been reported to be expressed in the $\mathrm{BBB}$ and could mediate the uptake of these drug (Amphoux et al., 2006) (Lin et al., 2010). Dos Santos Pereira et al. and Takano et al. reported that amisulpride and sulpiride were substrates of OCT1 (Dos Santos Pereira et al., 2014; Takano et al., 2017). Sekhar et al. also reported that amisulpride and haloperidol were transported by OCT1 (Sekhar et al., 2019). In addition, Kang et al. demonstrated that the neurotoxic pyridinium metabolites of haloperidol were substrates of OCT1, and pretreatment with OCT1 inhibitors verapamil, cimetidine, phenoxybenzylamine, and corticosterone could significantly inhibit the accumulations of these metabolites in Caco-2 cells (Kang et al., 2006). However, because certain drugs such as amisulpride can be a substrate of multiple transporters in different cells, sometimes OCT1mediated DDIs involved these drugs may not be evident. For example, an inhibitor of OCT1, did not change the uptake rate of amisulpride in hCMEC/D3 cells but could inhibit the uptake of sulpiride, leading to a reduction of intracellular sulpiride accumulation (Dos Santos Pereira et al., 2014). Amantadine could increase the accumulation of amisulpride in bEnd. 3 cells, but it had no effect in hCMEC/D3 cells. In contrast, prazosin could reduce the uptake of amisulpride in hCMEC/ D3 cells but not in bEnd. 3 cells. The accumulation of amisulpride was not affected by haloperidol in either cell line (Sekhar et al., 2017). Conversely, the uptake of haloperidol could be significantly reduced by amantadine, prazosin and amisulpride in Caco-2 cells (Kang et al., 2006).

Some other antidepressants and antipsychotics may have a potential inhibitory effect on OCT1 activity (Ahlin et al., 2008). Haenisch et al. reported that at the concentrations relevant to their clinical plasma levels, a wide range of pharmacologically different antidepressants and antipsychotics could inhibit the activity of human OCT1 by more than $20 \%$, thereby likely interfering with the pharmacokinetics of OCT1 substrates in the liver, kidney and brain (Haenisch et al., 2012).

\subsection{Anti-Fungal Drugs}

Ketoconazole and itraconazole are antifungal medications, and they are generally regarded as clinically importantly CYP3A4/5 inhibitors (Varhe et al., 1994; Greenblatt, 2016). Recently, Vermeer et al. reported that ketoconazole and itraconazole are inhibitors of OCT1. The two drugs could inhibit the uptake of quinidine in vitro (Vermeer et al., 2016). However, they are not OCT1 substrates as the data indicated that they were not transported into the liver by hepatic OCT1 (Higgins et al., 2014).

Isavuconazole, a novel triazole antifungal prodrug, is used to treat invasive mucormycosis and aspergillosis (Maertens et al., 
2016; Marty et al., 2016). In a clinical study, Yamazaki et al. has provided data in support of isavuconazole as an inhibitor of OCT1 (Yamazaki et al., 2017). Isavuconazole treatment could significantly alter the pharmacokinetics of metformin, such as the increase of its AUC and $\mathrm{C}_{\max }$. Of note, isavuconazole $\mathrm{PK}$ was unaffected by metformin treatment.

\subsection{Anti-Malarial Drugs}

It has been reported that anti-malarials such as amodiaquine, primaquine, proguanil, pyrimethamine can significantly reduce the cellular activity of OCT1 (van der Velden et al., 2017). Moreover, proguanil and cycloguanil are found to be the substrates of OCT1 and other organic cation transporters including OCT2, MATE1 and MATE2-K. Because the endemic of malaria, HIV/AIDS and tuberculosis is always overlapped geographically, the incidence of co-infection among patients is high. Multiple drugs are required for the treatment of co-infection. As described above, the interaction with OCT1 is also common with anti-viral and anti-tuberculosis drugs. OCT1-mediated DDIs are expected in concurrent therapy for the co-infection.

\subsection{Anti-Parkinson Drugs}

Pramipexole is a dopamine receptor agonist, which is used to treat the symptoms of Parkinson disease. The drug has been reported as a substrate for rat OCT1 (Ishiguro et al., 2005). However, a study by Diao et al. indicated that pramipexole was not a substrate for human OCT1 (Diao et al., 2010). Instead, pramipexole was identified as a substrate of human OCT2 and OCT3. It is likely that the absorption of pramipexole in human intestine may be mediated by OCT3 and possibly OCT2. In addition, OCT2 and OCT3 may function to transport pramipexole in renal elimination and brain distribution, respectively.

\subsection{Anti-Platelet Drugs}

Clopidogrel (CP) is a widely used anti-platelet drug. It is either metabolized by cytochrome P450s into active metabolites in the liver or hydrolyzed by esterase to clopidogrel carboxylate (CPC). A study by Li et al. indicated that CP could strongly inhibit the uptake of lamivudine and amantadine mediated by human OCT1 in MDCK-hOCT1 cells (Li et al., 2014a). CPC could also significantly reduce the uptake of lamivudine in these cells but only had slight inhibition on the uptake of amantadine. The likelihood of clinical DDIs between CP and amantadine is expected to be low. On the other hand, although CP itself inhibits the uptake of OCT1 substrates such as metformin, lamivudine and amantadine, in consideration of the short duration of $\mathrm{CP}$ in the liver and a low plasma concentration, $\mathrm{Li}$ et al. thought that the DDI mediated by OCT1 between CP and those substrate drugs may not be serious in vivo. Future clinical observation is needed to confirm this postulation.

\subsection{Anti-Protozoal Drugs}

Pentamidine and furamidine are used to prevent severe lung infection in AIDS patients. They belong to a class of drugs called antiprotozoals. Ming et al. have shown that pentamidine and furamidine are good substrates of hOCT1. Ranitidine, a known OCT1 inhibitor, could significantly reduce the cytotoxicity of pentamidine and furamidine in CHO-hOCT1 cells (Ming et al., 2009). In addition, Sekhar et al. reported that pentamidine was a substrate for OCT1 transporter at the BBB (Sekhar et al., 2017). The OCT1 inhibitor amantadine could decrease the accumulation of pentamidine in hCMEC/D3 and bEnd.3 cell lines. However, another OCT1 inhibitor prazosin decreased pentamidine accumulation only in hCMEC/D3 cells, but not in bEnd. 3 cells. Those OCT1 inhibitors may be non-specific, and other transporters might contribute to the cellular uptake of pentamidine as well. The significance of OCT1 in mediating a DDI between antiprotozoals and other drugs has yet to be confirmed.

\subsection{Anti-Tuberculosis Drugs}

The anti-tuberculosis (anti-TB) drugs are divided into two categories according to use frequency and efficacy: first-line and second-line anti-TB drugs. Among the approved drugs, the first-line essential agents that form the core of treatment regimens are rifampin (RIF), isoniazid (INH), and ethambutol (EMB) (Sotgiu et al., 2015).

Te Brake et al. reported that EMB is a substrate of OCT1. Moxifloxacin, which was characterized as a potent inhibitor of OCT1, could significantly inhibit the cellular transport of EMB (Te Brake et al., 2016). Later, Parvez et al. confirmed that EMB, amoxicillin, INH and prothionamide were novel substrates of OCT1 and as expected, the OCT1 inhibitor verapamil could strongly reduce their cellular uptake (Parvez et al., 2018). In addition, they found that the DDI indices of OCT1-mediated uptake of EMB and prothionamide were similar to that of verapamil, suggesting a strong in vivo potential of DDIs for these drugs with others.

Moreover, the DDI analysis by Pan et al. indicated that EMB has a strong potential for DDIs mediated by human OCT1 and OCT3 which are expressed in intestinal epithelial cells and hepatocytes. These DDIs may result in an altered absorption, distribution and excretion of the cationic drugs which are coadministered with EMB (Pan et al., 2013). For example, TB patients with coexisting diabetes or HIV might develop significant DDIs when co-treated with EMB and an OCT1/ OCT3 substrate (e.g., lamivudine or metformin).

In addition, Parvez et al. reported that pyrazinamide, levofloxacin, and RIF could significantly inhibit OCT1mediated metformin uptake in HEK-OCT1 cells (Parvez et al., 2016). With a static model-based approach to assess the correlation between the inhibitory potential of anti-TB drugs and the prognosis, they predicted a strong possibility of DDIs for these drugs interacting with other OCT1 substrate drugs in vivo on affecting anti-TB efficacy.

Para-aminosalicylic acid (PAS) is a second-line anti-TB drug used to treat multidrug resistant tuberculosis. The results by Parvez et al. indicated that PAS is a substrate of several transporters including OCT1 (Parvez et al., 2017). While they demonstrated that metformin effectively inhibited PAS uptake via OCT1, their estimated DDI index did not support the existence of clinical DDIs. They also found that omeprazole, 
lansoprazole, cimetidine, verapamil and quinidine could decrease the levels of OCT1-mediated PAS uptake in vitro. In contrast to that between PAS and metformin, the estimated DDI index values for the interaction between PAS and these OCT1 inhibitors were greatly higher than the cutoff and suggested possible clinical DDIs. The data are useful for future studies in patients to understand PAS disposition and clinical efficacy.

\subsection{Antiviral Drugs}

Many antiviral drugs have shown a binding affinity to OCT1 as substrates or inhibitors. Lamivudine, which is used to treat hepatitis B and HIV infection, belongs to a class of medications called nucleoside reverse transcriptase inhibitors (NRTIs). Human OCTs are characterized as important determinants of intracellular and plasma concentrations of lamivudine because they transport lamivudine and express in not only the organs of lamivudine disposition, such as liver and kidney, but also immune cells and excretory tissues that are critical to lamivudine action (Minuesa et al., 2009). Zalcitabine, another NRTI, has been demonstrated as a highly efficient substrate of OCT1 and OCT2 as well (Jung et al., 2008). Interestingly, the NRTIs abacavir and azidothymidine (zidovudine), the protease inhibitors nelfinavir, ritonavir, saquinavir, indinavir, and the anti-infective drugs pentamidine, trimethoprim are all high affinity inhibitors of OCT1 and OCT2. The concomitant administration of lamivudine and these potent OCT inhibitors is common in the regimen of highly active antiretroviral therapy (HAART). The DDIs may be of great significance in clinical practice, particularly for the pharmacokinetics, of lamivudine (Zhang et al., 2000; Jung et al., 2008; Minuesa et al., 2009; Jung et al., 2013; Arimany-Nardi et al., 2016). Consistently, Jung et al. documented that the addition of OCT1 and OCT2 inhibitors such as ritonavir and nelfinavir could reduce the accumulation of lamivudine in the CD4 cells of HIV-infected patients (Jung et al., 2013).

Efavirenz is antiviral drug in another class of medications called non-nucleoside reverse transcriptase inhibitors. It decreases the amount of HIV in the blood. Efavirenz has been demonstrated as an inhibitor of OCT1 by using hOCT1overexpressing MDCK and KCL2 cells. The drug could inhibit the cellular transport and intracellular accumulation of lamivudine (Moss et al., 2015; Ceckova et al., 2018). The possible DDIs should be considered when co-administering efavirenz to HIV patients with other drugs.

Daclatasvir is used in combination with other medications to treat hepatitis $\mathrm{C}$ infection. Daclatasvir is a reversible and timedependent inhibitor of OCT1 and OCT2 in cellular studies (Gandhi et al., 2018). However, Smolders et al. demonstrated that daclatasvir did not affect PK and PD parameters of the OCT1 substrate metformin in healthy subjects (Smolders et al., 2017). Interestingly, when daclatasvir was combined with metformin, the number of adverse events increased in human subjects. It has been suggested to monitor the adverse events during the treatment of type 2 diabetes mellitus (T2DM) patients with $\mathrm{HCV}$ infection under the combination treatment of daclatasvir and metformin.
In addition, Takeda et al. found that human OAT1 and hOCT1 are responsible for the renal transport of acyclovir and ganciclovir (Takeda et al., 2002). Caution should be taken when these antiviral drugs are used in conjunction with other drugs that share the same transporters for urinary tract excretion. Concomitant administration of these drugs may cause an increase in their plasma concentrations, leading to adverse drug reactions.

\subsection{Beta-Adrenergic Receptor Blockers}

Nadolol is a beta blocker that can be used alone or in combination with other drugs to treat high blood pressure. It is also used to prevent angina. Misaka et al. reported that nadolol was a substrate of human OCT1 and that OCT1-mediated nadolol uptake could be inhibited by cimetidine and trimethoprim in vitro (Misaka et al., 2016). In addition, carvedilol, another beta blocker, could inhibit metformin uptake mediated by human OCT1 and mouse OCT1 (Guo et al., 2018). These data will contribute to future human studies on OCT1-mediated DDIs involved beta blockers.

\subsection{Beta2-Adrenergic Receptor Agonists}

Beta-2-adrenergic agonists are first line agents in the treatment of asthma and other pulmonary disorders, such as chronic obstructive pulmonary disease. In a study by Salomon et al., $\beta 2$ - adrenergic agonists such as salbutamol sulfate, formoterol fumarate, and salmeterol xinafoate were found to be substrates and inhibitors of OCT1 in human respiratory epithelial cells (Salomon et al., 2015). They demonstrated that the cellular uptake was mediated by hOCT1 in a time- and concentration-dependent manner for salbutamol, which was sensitive to inhibition by the OCT1 inhibitor verapamil. There was expression of hOCT1 and other organic cation transporters in human pulmonary epithelial cells. Therefore, OCT1 may be involved in the pulmonary disposition of beta2-adrenergic receptor agonists. Certain nonsteroidal anti-inflammatory drugs (NSAIDs) were found to effectively inhibit the activity of OCT1 in leukemic cells (Wang et al., 2012). Mamlouk et al. found that the uptake of salbutamol was decreased in the presence of NSAIDs and proposed that NSAIDs could inhibit the absorption of salbutamol across the bronchial epithelium via the effects on OCT transporters (Mamlouk et al., 2013). In consideration of the highly polymorphic SLC22A1 gene and a wide spectrum of substrates and inhibitors for this transporter protein, the DDIs mediated by OCT1 between drugs of this class and others may be clinically important.

\subsection{Flavonoids}

Flavonoids, such as phloretin and quercetin are secondary plant metabolites that can be found in different vegetables and fruits. Some flavonoids have been reported to possess health protective effects against cancer and cardiovascular diseases. There are studies indicating that quercetin is not a potent OCT1 inhibitor (Mandery et al., 2012; Glaeser et al., 2014). However, quercetin was characterized as a substrate of OCT1. In HEK293hOCT1 cells, the uptake of quercetin could be significantly reduced by the OCT1 inhibitors such as amipamine, quinidine, and trimethoprim. There is also evidence in support 
of flavonoids as OCT1 inhibitors. Mimura et al. reported that hOCT1-mediated atenolol transport could be inhibited by rhestin and quercetin, which are the main components of apple juice, as well as several other flavonoids (Mimura et al., 2015). In a cellular study by Taur et al., quercetin could inhibit the activity of the OCT system and reduce the intracellular accumulation of the substrate tetraethylammonium in LLC-PK1 cells (Taur and Rodriguez-Proteau, 2008). The flavonoids, such as quercetin, have the potential to alter the disposition profile of certain therapeutics by which cellular transport is mediated by cation transporters including OCT1.

\subsection{Hypoglycemic Drugs}

Diabetic patients frequently have to be treated with more than one drug. Among the anti-diabetic drugs, metformin is the most widely studied in relation to OCT1 function (Inzucchi et al., 2012). Previous reports mainly focus on the effect of metformin on the disposition of other drugs. However, recent studies have shown that some drugs used in combination with metformin in the clinical treatment of diabetes can also affect the disposal process of metformin through OCT1 (Dawed et al., 2019) (Table 2). In addition, studies have shown that the intestinal OCT1 and concomitant medications play a vital role in the gastrointestinal adverse effects of metformin (Dujic et al., 2016). When metformin is used in combination with proton pump inhibitors (PPIs), tricyclic antidepressants (TCAs) or codeine, the likelihood of metformin intolerance is greatly increased (Stage et al., 2016).

Naringenin is a colorless flavorless flavanone. Mata Mofo et al. reported that naringenin could up-regulate the expression of human OCT1, thereby improving the symptoms associated with diabetes (e.g., weight gain, heavy drinking, metabolic acidosis) (Mato Mofo et al., 2020). The diabetic patients treated with metformin may thus take grapefruit juice of which the predominant flavanone is naringenin. Stage et al. analyzed 32 drugs which may inhibit metformin transporters to assess the risk of early discontinuation of metformin (Stage et al., 2016). The odds ratio for early discontinuation of metformin was only found to be associated with codeine use. The results indicated that co-administration of codeine may be associated with a risk of early discontinuation of metformin.

Although deletion of Slc22a1 gene in mice did not cause any apparent physiological defects, OCT1 can transport various endogenous metabolites, suggesting a physiological role by OCT1 activity in drug action (Chen et al., 2014). In addition to the transport of metformin, OCT1 may be a target for metformin (Chen et al., 2014; Chen et al., 2015). Metformin can competitively inhibit OCT1-mediated thiamine uptake in cells, resulting in reduced intestinal and systemic plasma thiamine levels, as well as liver thiamine levels. Modulation of thiamine levels via OCT1 by metformin might be critically important in its beneficial effects in treatment of diabetes, obesity, hepatic steatosis and cancer.

In recent years, gut microbiota has been linked to diabetes and other metabolic disorders. Metformin has an effect on the balance of gut microbiota. A study by Barengolts et al. found that the interaction between opioids and metformin had a significant effect on the abundance of bifidobacteria in the gut (Barengolts et al., 2018). Metformin treatment was associated with a decrease in the abundance of gut bifidobacterium in opioid users. In contrast, in the opioid non-users, metformin treatment was associated with an increase in the abundance of gut bifidobacteria. While the exact mechanism remains unclear, the authors hypothesized that opioids were inhibitors of OCT1, leading to a higher level of metformin in the blood and/or tissues which contributes to the observation. Response to metformin can be affected by other OCT1 inhibitors. Cho et al. indicated that verapamil could reduce metformin's ability to lower blood glucose, but did not affect its pharmacokinetics (Cho et al., 2014). One of the reasons is that verapamil likely act as a potent competitive OCT1 inhibitor, preventing metformin uptake into the liver. Interaction between verapamil and metformin in patients with hypertension and T2DM may thus affect their efficacy and safety. In addition, OCT1 inhibitors were regarded as important players in metformin gastrointestinal side effects experienced by up to $20-30 \%$ of patients (Dujic et al., 2015). The DDI between metformin and an OCT1 inhibitor could become even complex in individuals with SLC22A1 genetic polymorphisms (Dujic et al., 2016).

Common genetic variation of the SLC22A1 gene could reduce the transport of substrates such as metformin in the liver (Shu et al., 2007; Ahlin et al., 2011). Compared with fully functional hOCT1- reference (NM_003057), the polymorphic hOCT1 proteins such as M420del and R61C were more susceptible to the inhibition by inhibitors. Specifically, the uptake of metformin via hOCT1- M420del was subjected to more inhibition by clinically relevant concentrations of verapamil, as compared to the hOCT1- reference. The enhanced sensitivity to drug inhibition toward OCT1 variants may lead to an increased risk of DDIs in individuals with these variants.

There are additional reports on DDIs between metformin and clinical used drugs. Frias et al. reported that in subjects who did not reach the maximal goal of $\mathrm{HbAlc}$ with a sub-maximal dose of metformin, the addition of sitagliptin improved the glycemic response and glycated hemoglobin goals, while the safety and tolerability were similar with metformin treatment alone (Frias et al., 2019). A possible mechanism is that the inhibition of OCT1 by sitagliptin could reduce the phosphorylation of AMPK, the first step in metformin's action (Choi et al., 2010). In addition, Cho et al. found that rifampin can up-regulate the expression of SLC22A1 gene in peripheral blood cells, increase the concentration of metformin in the blood and enhance the hypoglycemic effect of metformin (Cho et al., 2011). Rifampin could also increase renal tubule secretion of metformin. In patients with T2DM and tuberculosis, the interaction between metformin and rifampicin may thus affect drug safety and efficacy. On the other hand, because the most toxic side effect of metformin, lactic acidosis, is a dose-dependent effect, reducing the dose of metformin may reduce the risk of lactic acidosis.

In vitro evidence has also suggested that OCT 1 may be able to mediate an interaction of metformin with other clinical drugs or diet supplements. For example, green tea and its most abundant catechin epigallocatechin gallate (EGCG) could inhibit the 
transport of metformin mediated by hOCT1 in cellular studies (Knop et al., 2015; Albassam and Markowitz, 2017). Interestingly, the inhibitory effect by green tea even exceeded that by EGCG. Bachmakov et al. also reported that the anti-diabetic repaglinide and rosiglitazone could significantly inhibit hOCT1-mediated metformin uptake in cells (Bachmakov et al., 2008).

Of note, DDIs in vitro may not necessarily translate into a clinical DDI. Recent in vitro studies have found that PPIs may interfere with the effectiveness of metformin (Nies et al., 2011a). However, Flory et al. has shown that the use of PPIs did not impair the effectiveness of metformin and that PPIs themselves had no significant clinical impact on glycemic control (Flory et al., 2015). Metformin was at least as effective in reducing glycosylated hemoglobin in patients with chronic PPIs treatment as in patients without PPIs treatment. Peficitinib, a pan-Janus kinase inhibitor, is used to treat rheumatoid arthritis (Takeuchi et al., 2016). Peficitinib has been shown to inhibit the uptake of metformin in hOCT1-overexpressing cells (Shibata et al., 2020). However, in clinical studies, the AUC, $\mathrm{C}_{\max }$ and $\mathrm{CL}_{\mathrm{R}}$ of metformin were only slightly reduced by peficitinib treatment in healthy male subjects. As metformin is a relatively safe and generally well tolerated by patients, the interaction between peficitinib and metformin may not be clinically important and metformin dose adjustment may be not required. However, further clinical studies in patients are always needed to confirm the assumption based on in vitro findings and those from healthy human subjects.

\subsection{6 $\mathrm{H}_{2}$ Receptor Antagonists}

Cimetidine, ranitidine and famotidine belong to a class of drugs called $\mathrm{H}_{2}$-receptor antagonists. These drugs have been reported as the substrates for OCTs but are used primarily as the inhibitors of OCTs in many studies (Barendt and Wright, 2002; Bourdet et al., 2005). Meyer et al. found that as a substrate or competitive inhibitor of OCT1, ranitidine could inhibit hOCT1-mediated uptake of morphine and metformin at clinically relevant concentrations (Meyer et al., 2017). In addition, the uptake of ranitidine was also affected by common genetic polymorphisms of SLC22A1 gene. However, although co-medication of ranitidine significantly reduced the rate of renal clearance of trospium chloride, the oral absorption and distribution did not change in healthy subjects (Abebe et al., 2020). Because of potential effects by disease status and genetic polymorphisms on transporter function, the clinically relevant impact of ranitidine on the pharmacokinetics of trospium chloride and other drugs in patients remain to be further delineated.

\subsection{Immunosuppressants}

Cyclosporine A (CsA) is a large lipophilic cyclic polypeptide. It can prevent organ rejection after transplant and is used to treat rheumatoid arthritis and psoriasis. In a cellular study, CsA was identified as an inhibitor of hOCT1 (Panfen et al., 2019). In particular, the inhibitory potency of CsA against hOCT1mediated metformin uptake was 50 -fold higher with CsA preincubation as compared to co-incubation. Interestingly, the difference in inhibitory potency between pre-incubation and co-inhibition with CsA seemed to be substrate-dependent. The $\mathrm{IC}_{50}$ shift ranged from $>1.2$ - to 50.2 -fold with different substrates.
While it would be interesting to understand the mechanism underlying the shift of hOCT1 inhibition by CsA with different incubation conditions, the potent and persistent inhibitory effect on hOCT1 after exposure to CsA implies hOCT1-mediated DDIs with other drugs in patients.

\subsection{Muscarinic Antagonists}

Trospium chloride (TC) is a muscarinic antagonist that is used to treat overactive bladder and symptoms of urinary frequency, urgency and incontinence (Wenge et al., 2011). TC is not completely absorbed from the gut. While it is widely distributed after absorption, it does not significantly pass the BBB (Bexten et al., 2015). TC can be eliminated from the kidney, liver, and intestine. It has been characterized as a substrate of several transporters including OCT1, P-glycoprotein, and OATP1A2. In cell studies, TC was taken up by human bladder urothelial cells through a mechanism that is susceptible to the inhibition by verapamil, an inhibitor toward several transporters. Although OCT1 may contribute to the disposition of TC, currently there is no evidence in support of any serious OCT1-mediated DDIs for this drug.

\subsection{Opioids}

Morphine, an opioid receptor agonist, has been determined as a substrate of OCT1 (Balyan et al., 2017). Zhu et al. has shown that both OCT1 and OCT2 can mediate the cellular uptake of morphine (Zhu et al., 2018). Moreover, irinotecan could alter the distribution of morphine in vivo in mice by inhibiting mouse OCT1 activity. In addition, cellular hOCT1-mediated uptake of morphine was found to be inhibited by a variety of inhibitors, including irinotecan, verapamil, ondansetron, imipramine, codeine, amitriptyline, tropisetron, fluoxetine, and clomipramine, at the concentrations relevant to those at the portal vein in patients receiving these inhibitors (Tzvetkov et al., 2013). Although the plasma concentrations of these drugs are too low to inhibit the activity of OCT1, these drugs may still have a potential to cause DDIs with morphine because their oral administration may result in a higher concentration in the hepatic portal vein. However, morphine and codeine by themselves may have very moderate inhibitory effects on OCT1-mediated drug uptake, due to their low portal vein concentrations following oral administration. Considering that those patients requiring morphine for pain relief commonly receive concomitant medications, clinicians should be aware that the therapeutic and/or toxic effects of morphine may be altered by the co-administrated inhibitors and/or substrates of OCT1, such as irinotecan.

\subsection{Vitamins}

Thiamine, also known as vitamin B1, is found in foods such as cereals, whole grains, beans, meat, nuts and peas. It plays an important role in the breakdown of carbohydrates from foods into intermediate metabolites needed by the body. Thiamine has been identified as a substrate of OCT1 (Kato et al., 2015). However, multiple transporters may mediate the hepatocellular uptake of thiamine. The hOCT1-mediated uptake of thiamine may be only physiologically relevant at high concentrations, 
whereas other transporters are responsible for thiamine uptake into the liver at typical blood concentrations (Jensen et al., 2020). In the intestine, while the absorption of thiamine has been reported to be mediated by thiamine transporters ThTr1 and/ or $\operatorname{ThT} 2$, there is also contribution by OCT transporters, most likely by OCT1 and/or OCT3 (Lemos et al., 2012). The findings of thiamine as an OCT1 inhibitor have implicated an interaction mediated by OCT1 between nutrients and drugs, especially in patients who have been chronically treated with certain drugs and under a special diet. For example, as discussed above, there is potential OCT1-mediated interaction between thiamine and metformin in T2DM patients (Chen et al., 2014).

\section{CLOSING REMARKS}

In recent years, more and more attention has been paid to OCTs in the fields of clinical pharmacology and pharmaceutical research. Among these OCTs, OCT1 is widely distributed in different tissues with an extremely high level in the liver. A broad spectrum of substrates and inhibitors has been characterized for this transporter. Increasing evidence has indicated that OCT1

\section{REFERENCES}

Abebe, B. T., Weiss, M., Modess, C., Tadken, T., Wegner, D., Meyer, M. J., et al. (2020). Pharmacokinetic drug-drug interactions between trospium chloride and ranitidine substrates of organic cation transporters in healthy human subjects. J. Clin. Pharmacol. 60, 312-323. doi:10.1002/ jcph. 1523

Ahlin, G., Karlsson, J., Pedersen, J. M., Gustavsson, L., Larsson, R., Matsson, P., et al. (2008). Structural requirements for drug inhibition of the liver specific human organic cation transport protein 1. J. Med. Chem. 51, 5932-5942. doi:10. $1021 / j m 8003152$

Ahlin, G., Chen, L., Lazorova, L., Chen, Y., Ianculescu, A. G., Davis, R. L., et al. (2011). Genotype-dependent effects of inhibitors of the organic cation transporter, OCT1: predictions of metformin interactions. Pharmacogenomics J. 11, 400-411. doi:10.1038/tpj.2010.54

Al-Abdulla, R., Lozano, E., Macias, R. I. R., Monte, M. J., Briz, O., O’rourke, C. J., et al. (2019). Epigenetic events involved in organic cation transporter 1dependent impaired response of hepatocellular carcinoma to sorafenib. $\mathrm{Br}$. J. Pharmacol. 176, 787-800. doi:10.1111/bph.14563

Albassam, A. A., and Markowitz, J. S. (2017). An appraisal of drug-drug interactions with green tea (camellia sinensis). Planta Med. 83, 496-508. doi:10.1055/s-0043-100934

Amphoux, A., Vialou, V., Drescher, E., Brüss, M., Mannoury La Cour, C., Rochat, C., et al. (2006). Differential pharmacological in vitro properties of organic cation transporters and regional distribution in rat brain. Neuropharmacology 50, 941-952. doi:10.1016/j.neuropharm.2006.01.005

Arimany-Nardi, C., Minuesa, G., Keller, T., Erkizia, I., Koepsell, H., MartinezPicado, J., et al. (2016). Role of human organic cation transporter 1 (hOCT1) polymorphisms in lamivudine (3TC) uptake and drug-drug interactions. Front. Pharmacol. 7, 175. doi:10.3389/fphar.2016.00175

Bachmakov, I., Glaeser, H., Fromm, M. F., and König, J. (2008). Interaction of oral antidiabetic drugs with hepatic uptake transporters: focus on organic anion transporting polypeptides and organic cation transporter 1. Diabetes 57, 1463-1469. doi:10.2337/db07-1515

Balyan, R., Zhang, X., Chidambaran, V., Martin, L. J., Mizuno, T., Fukuda, T., et al. (2017). OCT1 genetic variants are associated with postoperative morphinerelated adverse effects in children. Pharmacogenomics 18, 621-629. doi:10. 2217/pgs-2017-0002 might be an important mediator for DDIs of clinical significance. However, the confirmed DDIs mediated by OCT1 in human subjects remain limited. A major reason is that an effective and convenient tool to probe OCT1 activity in humans has yet to be discovered and validated. OCT1 is highly polymorphic, with multiple common variants leading to functional alteration. The effort to study the DDIs of OCT1 substrates and inhibitors in the patients with different OCT1 genotypes may yield important clinical evidence in the near future. Current effort in characterizing the interaction of OCT1 with an increasing number of compounds will bring us valid probe drugs to assess OCT1 function in patients and lead to appreciation of its clinical importance in drug disposition and response. Our understanding of OCT1-mediated DDIs will eventually have an impact on optimization of pharmacotherapy in order to improve drug efficacy and avoid unnecessary DDIs.

\section{AUTHOR CONTRIBUTIONS}

SZ: Manuscript draft; YS and SZ: manuscript revision; All authors have read and approved the final version of the manuscript.

Barendt, W. M., and Wright, S. H. (2002). The human organic cation transporter (hOCT2) recognizes the degree of substrate ionization. J. Biol. Chem. 277, 22491-22496. doi:10.1074/jbc.M203114200

Barengolts, E., Green, S. J., Eisenberg, Y., Akbar, A., Reddivari, B., Layden, B. T., et al. (2018). Gut microbiota varies by opioid use, circulating leptin and oxytocin in African American men with diabetes and high burden of chronic disease. PLoS One 13, e0194171. doi:10.1371/journal.pone. 0194171

Belzer, M., Morales, M., Jagadish, B., Mash, E. A., and Wright, S. H. (2013). Substrate-dependent ligand inhibition of the human organic cation transporter OCT2. J. Pharmacol. Exp. Ther. 346, 300-310. doi:10.1124/ jpet.113.203257

Bexten, M., Oswald, S., Grube, M., Jia, J., Graf, T., Zimmermann, U., et al. (2015). Expression of drug transporters and drug metabolizing enzymes in the bladder urothelium in man and affinity of the bladder spasmolytic trospium chloride to transporters likely involved in its pharmacokinetics. Mol. Pharm. 12, 171-178. doi:10.1021/mp500532x

Bourdet, D. L., Pritchard, J. B., and Thakker, D. R. (2005). Differential substrate and inhibitory activities of ranitidine and famotidine toward human organic cation transporter 1 (hOCT1; SLC22A1), hOCT2 (SLC22A2), and hOCT3 (SLC22A3). J. Pharmacol. Exp. Ther. 315, 1288-1297. doi:10.1124/jpet.105. 091223

Boxberger, K. H., Hagenbuch, B., and Lampe, J. N. (2018). Ligand-dependent modulation of hOCT1 transport reveals discrete ligand binding sites within the substrate translocation channel. Biochem. Pharmacol. 156, 371-384. doi:10. 1016/j.bcp.2018.08.028

Brosseau, N., and Ramotar, D. (2019). The human organic cation transporter OCT1 and its role as a target for drug responses. Drug Metab. Rev. 51, 389-407. doi:10.1080/03602532.2019.1670204

Brouwer, K. L., Keppler, D., Hoffmaster, K. A., Bow, D. A., Cheng, Y., Lai, Y., et al. (2013). In vitro methods to support transporter evaluation in drug discovery and development. Clin. Pharmacol. Ther. 94, 95-112. doi:10.1038/ clpt.2013.81

Busch, A. E., Quester, S., Ulzheimer, J. C., Waldegger, S., Gorboulev, V., Arndt, P., et al. (1996). Electrogenic properties and substrate specificity of the polyspecific rat cation transporter rOCT1. J. Biol. Chem. 271, 32599-32604. doi:10.1074/jbc. 271.51.32599

Buss, I., Hamacher, A., Sarin, N., Kassack, M. U., and Kalayda, G. V. (2018). Relevance of copper transporter 1 and organic cation transporters 1-3 for 
oxaliplatin uptake and drug resistance in colorectal cancer cells. Metallomics 10, 414-425. doi:10.1039/c7mt00334j

Ceckova, M., Reznicek, J., Deutsch, B., Fromm, M. F., and Staud, F. (2018). Efavirenz reduces renal excretion of lamivudine in rats by inhibiting organic cation transporters (OCT, Oct) and multidrug and toxin extrusion proteins (MATE, Mate). PLoS One 13, e0202706. doi:10.1371/journal.pone.0202706

Chemuturi, N. V., and Donovan, M. D. (2007). Role of organic cation transporters in dopamine uptake across olfactory and nasal respiratory tissues. Mol. Pharm. 4, 936-942. doi:10.1021/mp070032u

Chen, E. C., Khuri, N., Liang, X., Stecula, A., Chien, H. C., Yee, S. W., et al. (2017). Discovery of competitive and noncompetitive ligands of the organic cation transporter 1 (OCT1; SLC22A1). J. Med. Chem. 60, 2685-2696. doi:10.1021/acs. jmedchem.6b01317

Chen, J., Ou, Y., Li, Y., Hu, S., Shao, L. W., and Liu, Y. (2017). Metformin extends C. elegans lifespan through lysosomal pathway. Elife. 6, e31268. doi:10.7554/elife. 31268

Chen, L., Shu, Y., Liang, X., Chen, E. C., Yee, S. W., Zur, A. A., et al. (2014). OCT1 is a high-capacity thiamine transporter that regulates hepatic steatosis and is a target of metformin. Proc. Natl. Acad. Sci. U.S.A. 111, 9983-9988. doi:10.1073/ pnas.1314939111

Chen, L., Yee, S. W., and Giacomini, K. M. (2015). OCT1 in hepatic steatosis and thiamine disposition. Cell Cycle 14, 283-284. doi:10.1080/15384101.2015. 1006532

Chen, M., Neul, C., Schaeffeler, E., Frisch, F., Winter, S., Schwab, M., et al. (2020). Sorafenib activity and disposition in liver cancer does not depend on organic cation transporter 1. Clin. Pharmacol. Ther. 107, 227-237. doi:10.1002/cpt.1588

Cherrington, N. J., Slitt, A. L., Li, N., and Klaassen, C. D. (2004). Lipopolysaccharide-mediated regulation of hepatic transporter mRNA levels in rats. Drug Metab. Dispos. 32, 734-741. doi:10.1124/dmd.32.7.734

Cho, S. K., Kim, C. O., Park, E. S., and Chung, J. Y. (2014). Verapamil decreases the glucose-lowering effect of metformin in healthy volunteers. Br. J. Clin. Pharmacol. 78, 1426-1432. doi:10.1111/bcp.12476

Cho, S. K., Yoon, J. S., Lee, M. G., Lee, D. H., Lim, L. A., Park, K., et al. (2011). Rifampin enhances the glucose-lowering effect of metformin and increases OCT1 mRNA levels in healthy participants. Clin. Pharmacol. Ther. 89, 416-421. doi:10.1038/clpt.2010.266

Choi, M. K., Jin, Q. R., Ahn, S. H., Bae, M. A., and Song, I. S. (2010). Sitagliptin attenuates metformin-mediated AMPK phosphorylation through inhibition of organic cation transporters. Xenobiotica 40, 817-825. doi:10.3109/00498254. 2010.520349

Ciarimboli, G., and Schlatter, E. (2005). Regulation of organic cation transport. Pflügers Archiv. 449, 423-441. doi:10.1007/s00424-004-1355-5

Colombo, I., Lheureux, S., and Oza, A. M. (2018). Rucaparib: a novel PARP inhibitor for BRCA advanced ovarian cancer. Drug Des. Dev. Ther. 12, 605-617. doi:10.2147/DDDT.S130809

Copple, B. L., Banes, A., Ganey, P. E., and Roth, R. A. (2002). Endothelial cell injury and fibrin deposition in rat liver after monocrotaline exposure. Toxicol. Sci. 65, 309-318. doi:10.1093/toxsci/65.2.309

Dawed, A. Y., Zhou, K., Van Leeuwen, N., Mahajan, A., Robertson, N., Koivula, R., et al. (2019). Variation in the plasma membrane monoamine transporter (PMAT) (encoded by SLC29A4) and organic cation transporter 1 (OCT1) (encoded by SLC22A1) and gastrointestinal intolerance to metformin in type 2 diabetes: an IMI DIRECT study. Diabetes Care 42, 1027-1033. doi:10.2337/ dc18-2182

Diao, L., Shu, Y., and Polli, J. E. (2010). Uptake of pramipexole by human organic cation transporters. Mol. Pharm. 7, 1342-1347. doi:10.1021/mp100036b

Dickens, D., Owen, A., Alfirevic, A., Giannoudis, A., Davies, A., Weksler, B., et al. (2012). Lamotrigine is a substrate for OCT1 in brain endothelial cells. Biochem. Pharmacol. 83, 805-814. doi:10.1016/j.bcp.2011.12.032

Dos Santos Pereira, J. N., Tadjerpisheh, S., Abu Abed, M., Saadatmand, A. R., Weksler, B., Romero, I. A., et al. (2014). The poorly membrane permeable antipsychotic drugs amisulpride and sulpiride are substrates of the organic cation transporters from the SLC22 family. AAPS J. 16, 1247-1258. doi:10.1208/ s12248-014-9649-9

Dujic, T., Causevic, A., Bego, T., Malenica, M., Velija-Asimi, Z., Pearson, E. R., et al. (2016). Organic cation transporter 1 variants and gastrointestinal side effects of metformin in patients with Type 2 diabetes. Diabet. Med. 33, 511-514. doi:10. $1111 /$ dme. 13040
Dujic, T., Zhou, K., Donnelly, L. A., Tavendale, R., Palmer, C. N., and Pearson, E. R. (2015). Association of organic cation transporter 1 with intolerance to metformin in type 2 diabetes: a GoDARTS study. Diabetes 64, 1786-1793. doi:10.2337/db14-1388

Ellawatty, W. E. A., Masuo, Y., Fujita, K. I., Yamazaki, E., Ishida, H., Arakawa, H., et al. (2018). Organic cation transporter 1 is responsible for hepatocellular uptake of the tyrosine kinase inhibitor pazopanib. Drug Metab. Dispos. 46, 33-40. doi:10.1124/dmd.117.076554

Flory, J., Haynes, K., Leonard, C. E., and Hennessy, S. (2015). Proton pump inhibitors do not impair the effectiveness of metformin in patients with diabetes. Br. J. Clin. Pharmacol. 79, 330-336. doi:10.1111/bcp.12506

Frias, J. P., Zimmer, Z., Lam, R. L. H., Amorin, G., Ntabadde, C., Iredale, C., et al. (2019). Double-blind, randomized clinical trial assessing the efficacy and safety of early initiation of sitagliptin during metformin uptitration in the treatment of patients with type 2 diabetes: the CompoSIT-M study. Diabetes Obes. Metabol. 21, 1128-1135. doi:10.1111/dom.13626

Gandhi, Y., Eley, T., Fura, A., Li, W., Bertz, R. J., and Garimella, T. (2018). Daclatasvir: a review of preclinical and clinical pharmacokinetics. Clin. Pharmacokinet 57, 911-928. doi:10.1007/s40262-017-0624-3

Geier, A., Macias, R. I., Bettinger, D., Weiss, J., Bantel, H., Jahn, D., et al. (2017). The lack of the organic cation transporter OCT1 at the plasma membrane of tumor cells precludes a positive response to sorafenib in patients with hepatocellular carcinoma. Oncotarget 8, 15846-15857. doi:10.18632/ oncotarget.15029

Giacomini, K. M., Giacomini, K. M., Huang, S. M., Tweedie, D. J., Benet, L. Z., Brouwer, K. L., et al. (2010). Membrane transporters in drug development. Nat. Rev. Drug Discov. 9, 215-236. doi:10.1038/nrd3028

Girardin, F. (2006). Membrane transporter proteins: a challenge for CNS drug development. Dialogues Clin. Neurosci. 8, 311-321. doi:10.31887/dcns.2006.8. $3 /$ fgirardin

Glaeser, H., Bujok, K., Schmidt, I., Fromm, M. F., and Mandery, K. (2014). Organic anion transporting polypeptides and organic cation transporter 1 contribute to the cellular uptake of the flavonoid quercetin. Naunyn-Schmiedeberg's Arch. Pharmacol. 387, 883-891. doi:10.1007/s00210-014-1000-6

Gong, L., Goswami, S., Giacomini, K. M., Altman, R. B., and Klein, T. E. (2012). Metformin pathways: pharmacokinetics and pharmacodynamics. Pharmacogenetics Genom. 22, 820-827. doi:10.1097/FPC.0b013e3283559b22

Gorboulev, V., Ulzheimer, J. C., Akhoundova, A., Ulzheimer-Teuber, I., Karbach, U., Quester, S., et al. (1997). Cloning and characterization of two human polyspecific organic cation transporters. DNA Cell Biol. 16, 871-881. doi:10. 1089/dna.1997.16.871

Graham, G. G., Punt, J., Arora, M., Day, R. O., Doogue, M. P., Duong, J. K., et al. (2011). Clinical pharmacokinetics of metformin. Clin. Pharmacokinet. 50, 81-98. doi:10.2165/11534750-000000000-00000

Greenblatt, D. J. (2016). Evidence-based choice of ritonavir as index CYP3A inhibitor in drug-drug interaction studies. J. Clin. Pharmacol. 56, 152-156. doi: $10.1002 /$ jcph.609

Gründemann, D., Gorboulev, V., Gambaryan, S., Veyhl, M., and Koepsell, H. (1994). Drug excretion mediated by a new prototype of polyspecific transporter. Nature 372, 549-552. doi:10.1038/372549a0

Guo, D., Yang, H., Li, Q., Bae, H. J., Obianom, O., Zeng, S., et al. (2018). Selective inhibition on organic cation transporters by carvedilol protects mice from cisplatin-induced nephrotoxicity. Pharm. Res. (N. Y.). 35, 204. doi:10.1007/ s11095-018-2486-2

Gupta, S., Wulf, G., Henjakovic, M., Koepsell, H., Burckhardt, G., and Hagos, Y. (2012). Human organic cation transporter 1 is expressed in lymphoma cells and increases susceptibility to irinotecan and paclitaxel. J. Pharmacol. Exp. Ther. 341, 16-23. doi:10.1124/jpet.111.190561

Haenisch, B., Drescher, E., Thiemer, L., Xin, H., Giros, B., Gautron, S., et al. (2012). Interaction of antidepressant and antipsychotic drugs with the human organic cation transporters hOCT1, hOCT2 and hOCT3. Naunyn-Schmiedeberg's Arch. Pharmacol. 385, 1017-1023. doi:10.1007/s00210-012-0781-8

Han, T. K., Everett, R. S., Proctor, W. R., Ng, C. M., Costales, C. L., Brouwer, K. L., et al. (2013). Organic cation transporter 1 (OCT1/mOct1) is localized in the apical membrane of Caco-2 cell monolayers and enterocytes. Mol. Pharmacol. 84, 182-189. doi:10.1124/mol.112.084517

Han, T. K., Proctor, W. R., Costales, C. L., Cai, H., Everett, R. S., and Thakker, D. R. (2015). Four cation-selective transporters contribute to apical uptake and 
accumulation of metformin in Caco-2 cell monolayers. J. Pharmacol. Exp. Ther. 352, 519-528. doi:10.1124/jpet.114.220350

Hanada, K., Nakai, K., Tanaka, H., Suzuki, F., Kumada, H., Ohno, Y., et al. (2012). Effect of nuclear receptor downregulation on hepatic expression of cytochrome P450 and transporters in chronic hepatitis C in association with fibrosis development. Drug Metabol. Pharmacokinet. 27, 301-306. doi:10.2133/ dmpk.dmpk-11-rg-077

Heise, M., Lautem, A., Knapstein, J., Schattenberg, J. M., Hoppe-Lotichius, M., Foltys, D., et al. (2012). Downregulation of organic cation transporters OCT1 (SLC22A1) and OCT3 (SLC22A3) in human hepatocellular carcinoma and their prognostic significance. BMC Cancer 12, 109. doi:10.1186/1471-240712-109

Herraez, E., Lozano, E., Macias, R. I., Vaquero, J., Bujanda, L., Banales, J. M., et al. (2013). Expression of SLC22A1 variants may affect the response of hepatocellular carcinoma and cholangiocarcinoma to sorafenib. Hepatology 58, 1065-1073. doi:10.1002/hep.26425

Higgins, J. W., Ke, A. B., and Zamek-Gliszczynski, M. J. (2014). Clinical CYP3A inhibitor alternatives to ketoconazole, clarithromycin and itraconazole, are not transported into the liver by hepatic organic anion transporting polypeptides and organic cation transporter 1. Drug Metab. Dispos. 42, 1780-1784. doi:10. 1124/dmd.114.058784

Hillgren, K. M., Keppler, D., Zur, A. A., Giacomini, K. M., Stieger, B., Cass, C. E., et al. (2013). Emerging transporters of clinical importance: an update from the International Transporter Consortium. Clin. Pharmacol. Ther. 94, 52-63. doi:10.1038/clpt.2013.74

Inzucchi, S. E., Bergenstal, R. M., Buse, J. B., Diamant, M., Ferrannini, E., Nauck, M., et al.American diabetes, A., and European association for the study of, D. (2012). Management of hyperglycemia in type 2 diabetes: a patient-centered approach: position statement of the American diabetes association (ADA) and the European association for the study of diabetes (EASD). Diabetes Care 35, 1364-1379. doi:10.2337/dc14-2441

Ishiguro, N., Saito, A., Yokoyama, K., Morikawa, M., Igarashi, T., and Tamai, I. (2005). Transport of the dopamine D2 agonist pramipexole by rat organic cation transporters OCT1 and OCT2 in kidney. Drug Metab. Dispos. 33, 495-499. doi:10.1124/dmd.104.002519

Jensen, O., Matthaei, J., Blome, F., Schwab, M., Tzvetkov, M. V., and Brockmöller, J. (2020). Variability and heritability of thiamine pharmacokinetics with focus on OCT1 effects on membrane transport and pharmacokinetics in humans. Clin. Pharmacol. Ther. 107, 628-638. doi:10.1002/cpt.1666

Jonker, J. W., and Schinkel, A. H. (2004). Pharmacological and physiological functions of the polyspecific organic cation transporters: OCT1, 2, and 3 (SLC22A1-3). J. Pharmacol. Exp. Ther. 308, 2-9. doi:10.1124/jpet.103.053298

Jung, N., Lehmann, C., Rubbert, A., Knispel, M., Hartmann, P., Van Lunzen, J., et al. (2008). Relevance of the organic cation transporters 1 and 2 for antiretroviral drug therapy in human immunodeficiency virus infection. Drug Metab. Dispos. 36, 1616-1623. doi:10.1124/dmd.108.020826

Jung, N., Lehmann, C., Rubbert, A., Schömig, E., Fätkenheuer, G., Hartmann, P., et al. (2013). Organic cation transporters OCT1 and OCT2 determine the accumulation of lamivudine in CD4 cells of HIV-infected patients. Infection 41, 379-385. doi:10.1007/s15010-012-0308-8

Kang, H. J., Lee, S. S., Lee, C. H., Shim, J. C., Shin, H. J., Liu, K. H., et al. (2006). Neurotoxic pyridinium metabolites of haloperidol are substrates of human organic cation transporters. Drug Metab. Dispos. 34, 1145-1151. doi:10.1124/ dmd.105.009126

Karbach, U., Kricke, J., Meyer-Wentrup, F., Gorboulev, V., Volk, C., Loffing-Cueni, D., et al. (2000). Localization of organic cation transporters OCT1 and OCT2 in rat kidney. Am. J. Physiol. Ren. Physiol. 279, F679-F687. doi:10.1152/ajprenal. 2000.279.4.F679

Kato, K., Moriyama, C., Ito, N., Zhang, X., Hachiuma, K., Hagima, N., et al. (2015). Involvement of organic cation transporters in the clearance and milk secretion of thiamine in mice. Pharm. Res. (N. Y.). 32, 2192-2204. doi:10.1007/s11095014-1608-8

Keating, G. M. (2017). Sorafenib: a review in hepatocellular carcinoma. Targeted Oncol. 12, 243-253. doi:10.1007/s11523-017-0484-7

Kimura, N., Masuda, S., Tanihara, Y., Ueo, H., Okuda, M., Katsura, T., et al. (2005). Metformin is a superior substrate for renal organic cation transporter OCT2 rather than hepatic OCT1. Drug Metabol. Pharmacokinet 20, 379-386. doi:10. 2133/dmpk.20.379
Knop, J., Misaka, S., Singer, K., Hoier, E., Müller, F., Glaeser, H., et al. (2015). Inhibitory effects of green tea and (-)-Epigallocatechin gallate on transport by OATP1B1, OATP1B3, OCT1, OCT2, MATE1, MATE2-K and P-glycoprotein. PLoS One 10, e0139370. doi:10.1371/journal.pone.0139370

Koehler, M. R., Wissinger, B., Gorboulev, V., Koepsell, H., and Schmid, M. (1997). The two human organic cation transporter genes SLC22A1 and SLC22A2 are located on chromosome 6q26. Cytogenet. Cell Genet. 79, 198-200. doi:10.1159/ 000134720

Koepsell, H., Gorboulev, V., and Arndt, P. (1999). Molecular pharmacology of organic cation transporters in kidney. J. Membr. Biol. 167, 103-117. doi:10. $1007 / \mathrm{s} 002329900475$

Koepsell, H., Lips, K., and Volk, C. (2007). Polyspecific organic cation transporters: structure, function, physiological roles, and biopharmaceutical implications. Pharm. Res. (N. Y.). 24, 1227-1251. doi:10.1007/s11095-007-9254-z

Koepsell, H. (2020). Organic cation transporters in health and disease. Pharmacol. Rev. 72, 253-319. doi:10.1124/pr.118.015578

Koepsell, H., Schmitt, B. M., and Gorboulev, V. (2003). Organic cation transporters. Rev. Physiol. Biochem. Pharmacol. 150, 36-90. doi:10.1007/ s10254-003-0017-x

Koepsell, H. (1998). Organic cation transporters in intestine, kidney, liver, and brain. Annu. Rev. Physiol. 60, 243-266. doi:10.1146/annurev.physiol.60.1.243

Koepsell, H. (2015). Role of organic cation transporters in drug-drug interaction. Expet Opin. Drug Metabol. Toxicol. 11, 1619-1633. doi:10.1517/17425255.2015. 1069274

Koepsell, H. (2013). The SLC22 family with transporters of organic cations, anions and zwitterions. Mol. Aspect. Med.34, 413-435. doi:10.1016/j.mam.2012.10.010

Kwon, M., Choi, Y. A., Choi, M. K., and Song, I. S. (2015). Organic cation transporter-mediated drug-drug interaction potential between berberine and metformin. Arch Pharm. Res. (Seoul). 38, 849-856. doi:10.1007/s12272-0140510-6

Lautem, A., Heise, M., Gräsel, A., Hoppe-Lotichius, M., Weiler, N., Foltys, D., et al. (2013). Downregulation of organic cation transporter 1 (SLC22A1) is associated with tumor progression and reduced patient survival in human cholangiocellular carcinoma. Int. J. Oncol. 42, 1297-1304. doi:10.3892/ijo.2013. 1840

Lemos, C., Faria, A., Meireles, M., Martel, F., Monteiro, R., and Calhau, C. (2012). Thiamine is a substrate of organic cation transporters in Caco-2 cells. Eur. J. Pharmacol. 682, 37-42. doi:10.1016/j.ejphar.2012.02.028

Li, J., Yang, Z., and Tuo, B. (2019). Role of OCT1 in hepatocellular carcinoma. Onco Targets Ther. 12, 6013-6022. doi:10.2147/OTT.S212088

Li, L., Lei, H., Wang, W., Du, W., Yuan, J., Tu, M., et al. (2018). Co-administration of nuciferine reduces the concentration of metformin in liver via differential inhibition of hepatic drug transporter OCT1 and MATE1. Biopharm Drug Dispos. 39, 411-419. doi:10.1002/bdd.2158

Li, L., Song, F., Tu, M., Wang, K., Zhao, L., Wu, X., et al. (2014a). In vitro interaction of clopidogrel and its hydrolysate with OCT1, OCT2 and OAT1. Int. J. Pharm. 465, 5-10. doi:10.1016/j.ijpharm.2014.02.003

Li, L., Tu, M., Yang, X., Sun, S., Wu, X., Zhou, H., et al. (2014b). The contribution of human OCT1, OCT3, and CYP3A4 to nitidine chloride-induced hepatocellular toxicity. Drug Metab. Dispos. 42, 1227-1234. doi:10.1124/ dmd.113.056689

Li, L., Sun, S., Weng, Y., Song, F., Zhou, S., Bai, M., et al. (2016). Interaction of six protoberberine alkaloids with human organic cation transporters 1,2 and 3. Xenobiotica. 46, 175-183. doi:10.3109/00498254.2015.1056283

Liang, R. F., Ge, W. J., Song, X. M., Zhang, J. P., Cui, W. F., Zhang, S. F., et al. (2020). Involvement of organic anion-transporting polypeptides and organic cation transporter in the hepatic uptake of jatrorrhizine. Xenobiotica 50, 479-487. doi:10.1080/00498254.2019.1651921

Liang, Y., Li, S., and Chen, L. (2015). The physiological role of drug transporters. Protein Cell. 6, 334-350. doi:10.1007/s13238-015-0148-2

Liao, M., Jaw-Tsai, S., Beltman, J., Simmons, A. D., Harding, T. C., and Xiao, J. J. (2020). Evaluation of in vitro absorption, distribution, metabolism, and excretion and assessment of drug-drug interaction of rucaparib, an orally potent poly(ADP-ribose) polymerase inhibitor. Xenobiotica 50 (9), 1032-1042. doi:10.1080/00498254.2020.1737759

Lin, C. J., Tai, Y., Huang, M. T., Tsai, Y. F., Hsu, H. J., Tzen, K. Y., et al. (2010). Cellular localization of the organic cation transporters, OCT1 and OCT2, in brain microvessel endothelial cells and its implication for MPTP transport 
across the blood-brain barrier and MPTP-induced dopaminergic toxicity in rodents. J. Neurochem. 114, 717-727. doi:10.1111/j.1471-4159.2010.06801.x

Lips, K. S., Volk, C., Schmitt, B. M., Pfeil, U., Arndt, P., Miska, D., et al. (2005). Polyspecific cation transporters mediate luminal release of acetylcholine from bronchial epithelium. Am. J. Respir. Cell Mol. Biol. 33, 79-88. doi:10.1165/rcmb. 2004-0363OC

Liu, C. X., Yi, X. L., Fan, H. R., Wu, W. D., Zhang, X., Xiao, X. F., et al. (2015). Effects of drug transporters on pharmacological responses and safety. Curr. Drug Metabol. 16, 732-752. doi:10.2174/138920021609151201112629

Liu, X., and Pan, G. (2019). Drug transporters in drug disposition, effects and toxicity. Singapore: Springer Singapore.

Lozano, E., Herraez, E., Briz, O., Robledo, V. S., Hernandez-Iglesias, J., GonzalezHernandez, A., et al. (2013). Role of the plasma membrane transporter of organic cations OCT1 and its genetic variants in modern liver pharmacology. BioMed Res. Int. 2013, 692071. doi:10.1155/2013/692071

Maertens, J. A., Raad, Ii., Marr, K. A., Patterson, T. F., Kontoyiannis, D. P., Cornely, O. A., et al. (2016). Isavuconazole versus voriconazole for primary treatment of invasive mould disease caused by Aspergillus and other filamentous fungi (SECURE): a phase 3, randomised-controlled, non-inferiority trial. Lancet. 387, 760-769. doi:10.1016/S0140-6736(15)01159-9

Mamlouk, M., Young, P. M., Bebawy, M., Haghi, M., Mamlouk, S., Mulay, V., et al. (2013). Salbutamol sulfate absorption across Calu-3 bronchial epithelia cell monolayer is inhibited in the presence of common anionic NSAIDs. J. Asthma. 50, 334-341. doi:10.3109/02770903.2013.773518

Mandery, K., Balk, B., Bujok, K., Schmidt, I., Fromm, M. F., and Glaeser, H. (2012). Inhibition of hepatic uptake transporters by flavonoids. Eur. J. Pharmaceut. Sci. 46, 79-85. doi:10.1016/j.ejps.2012.02.014

Marty, F. M., Ostrosky-Zeichner, L., Cornely, O. A., Mullane, K. M., Perfect, J. R., Thompson, G. R., 3rd, et al. (2016). Isavuconazole treatment for mucormycosis: a single-arm open-label trial and case-control analysis. Lancet Infect. Dis. 16, 828-837. doi:10.1016/S1473-3099(16)00071-2

Mato Mofo, E. P., Essop, M. F., and Owira, P. M. O. (2020). Citrus fruit-derived flavonoid naringenin and the expression of hepatic organic cation transporter 1 protein in diabetic rats treated with metformin. Basic Clin. Pharmacol. Toxicol. 127 (3), 211-220. doi:10.1111/bcpt.13407

Meyer, M. J., Seitz, T., Brockmöller, J., and Tzvetkov, M. V. (2017). Effects of genetic polymorphisms on the OCT1 and OCT2-mediated uptake of ranitidine. PLoS One 12, e0189521. doi:10.1371/journal.pone.0189521

Mimura, Y., Yasujima, T., Ohta, K., Inoue, K., and Yuasa, H. (2015). Functional identification of organic cation transporter 1 as an atenolol transporter sensitive to flavonoids. Biochem. Biophys. Rep. 2, 166-171. doi:10.1016/j.bbrep.2015. 06.005

Minematsu, T., and Giacomini, K. M. (2011). Interactions of tyrosine kinase inhibitors with organic cation transporters and multidrug and toxic compound extrusion proteins. Mol. Cancer Ther. 10, 531-539. doi:10.1158/1535-7163. MCT-10-0731

Ming, X., Ju, W., Wu, H., Tidwell, R. R., Hall, J. E., and Thakker, D. R. (2009). Transport of dicationic drugs pentamidine and furamidine by human organic cation transporters. Drug Metab. Dispos. 37, 424-430. doi:10.1124/dmd.108. 024083

Minuesa, G., Purcet, S., Erkizia, I., Molina-Arcas, M., Bofill, M., Izquierdo-Useros, N., et al. (2008). Expression and functionality of anti-human immunodeficiency virus and anticancer drug uptake transporters in immune cells. J. Pharmacol. Exp. Ther. 324, 558-567. doi:10.1124/jpet.107.131482

Minuesa, G., Volk, C., Molina-Arcas, M., Gorboulev, V., Erkizia, I., Arndt, P., et al. (2009). Transport of lamivudine [(-)-beta-L-2', $3^{\prime}$-dideoxy-3'-thiacytidine] and high-affinity interaction of nucleoside reverse transcriptase inhibitors with human organic cation transporters 1, 2, and 3. J. Pharmacol. Exp. Ther. 329, 252-261. doi:10.1124/jpet.108.146225

Misaka, S., Knop, J., Singer, K., Hoier, E., Keiser, M., Müller, F., et al. (2016). The nonmetabolized $\beta$-blocker nadolol is a substrate of OCT1, OCT2, MATE1, MATE2-K, and P-glycoprotein, but not of OATP1B1 and OATP1B3. Mol. Pharm. 13, 512-519. doi:10.1021/acs.molpharmaceut.5b00733

Mofo Mato, E. P., Guewo-Fokeng, M., Essop, M. F., and Owira, P. M. O. (2018). Genetic polymorphisms of organic cation transporter 1 (OCT1) and responses to metformin therapy in individuals with type 2 diabetes: a systematic review. Medicine (Baltim.). 97, e11349. doi:10.1097/MD.0000000000011349
More, S. S., Li, S., Yee, S. W., Chen, L., Xu, Z., Jablons, D. M., et al. (2010). Organic cation transporters modulate the uptake and cytotoxicity of picoplatin, a thirdgeneration platinum analogue. Mol. Cancer Ther. 9, 1058-1069. doi:10.1158/ 1535-7163.MCT-09-1084

Moss, D. M., Liptrott, N. J., Siccardi, M., and Owen, A. (2015). Interactions of antiretroviral drugs with the SLC22A1 (OCT1) drug transporter. Front. Pharmacol. 6, 78. doi:10.3389/fphar.2015.00078

Mukherjee, M., Pritchard, D. I., and Bosquillon, C. (2012). Evaluation of airinterfaced Calu- 3 cell layers for investigation of inhaled drug interactions with organic cation transporters in vitro. Int J Pharm. 426, 7-14. doi:10.1016/j. ijpharm.2011.12.036

Müller, J., Lips, K. S., Metzner, L., Neubert, R. H., Koepsell, H., and Brandsch, M. (2005). Drug specificity and intestinal membrane localization of human organic cation transporters (OCT). Biochem. Pharmacol. 70, 1851-1860. doi:10.1016/j. bcp.2005.09.011

Namisaki, T., Schaeffeler, E., Fukui, H., Yoshiji, H., Nakajima, Y., Fritz, P., et al. (2014). Differential expression of drug uptake and efflux transporters in Japanese patients with hepatocellular carcinoma. Drug Metab. Dispos. 42, 2033-2040. doi:10.1124/dmd.114.059832

Neuhoff, S., Ungell, A. L., Zamora, I., and Artursson, P. (2003). pH-dependent bidirectional transport of weakly basic drugs across Caco-2 monolayers: implications for drug-drug interactions. Pharm. Res. (N. Y.). 20, 1141-1148. doi:10.1023/a:1025032511040

Nies, A. T., Hofmann, U., Resch, C., Schaeffeler, E., Rius, M., and Schwab, M. (2011a). Proton pump inhibitors inhibit metformin uptake by organic cation transporters (OCTs). PLoS One 6, e22163. doi:10.1371/journal.pone.0022163

Nies, A. T., Koepsell, H., Damme, K., and Schwab, M. (2011b). Organic cation transporters (OCTs, MATEs), in vitro and in vivo evidence for the importance in drug therapy. Handb. Exp. Pharmacol. 201, 105-167. doi:10.1007/978-3-64214541-4_3

Nies, A. T., Koepsell, H., Winter, S., Burk, O., Klein, K., Kerb, R., et al. (2009). Expression of organic cation transporters OCT1 (SLC22A1) and OCT3 (SLC22A3) is affected by genetic factors and cholestasis in human liver. Hepatology. 50, 1227-1240. doi:10.1002/hep.23103

Nies, A. T., and Schwab, M. (2010). Organic cation transporter pharmacogenomics and drug-drug interaction. Expet Rev. Clin. Pharmacol. 3, 707-711. doi:10.1586/ ecp. 10.60

Nishimura, M., and Naito, S. (2005). Tissue-specific mRNA expression profiles of human ATP-binding cassette and solute carrier transporter superfamilies. Drug Metabol. Pharmacokinet. 20, 452-477. doi:10.2133/dmpk.20.452

Niu, J., Straubinger, R. M., and Mager, D. E. (2019). Pharmacodynamic drug-drug interactions. Clin. Pharmacol. Ther. 105, 1395-1406. doi:10.1002/cpt.1434

Ogasawara, K., Terada, T., Katsura, T., Hatano, E., Ikai, I., Yamaoka, Y., et al. (2010). Hepatitis C virus-related cirrhosis is a major determinant of the expression levels of hepatic drug transporters. Drug Metabol. Pharmacokinet. 25, 190-199. doi:10.2133/dmpk.25.190

Palleria, C., Di Paolo, A., Giofrè, C., Caglioti, C., Leuzzi, G., Siniscalchi, A., et al. (2013). Pharmacokinetic drug-drug interaction and their implication in clinical management. J. Res. Med. Sci. 18, 601-610.

Pan, X., Wang, L., Gründemann, D., and Sweet, D. H. (2013). Interaction of Ethambutol with human organic cation transporters of the SLC22 family indicates potential for drug-drug interactions during antituberculosis therapy. Antimicrob. Agents Chemother. 57, 5053-5059. doi:10.1128/AAC. 01255-13

Panfen, E., Chen, W., Zhang, Y., Sinz, M., Marathe, P., Gan, J., et al. (2019). Enhanced and persistent inhibition of organic cation transporter 1 activity by preincubation of cyclosporine A. Drug Metab. Dispos. 47, 1352-1360. doi:10. 1124/dmd.119.087197

Parvez, M. M., Kaisar, N., Shin, H. J., Jung, J. A., and Shin, J. G. (2016). Inhibitory interaction potential of 22 antituberculosis drugs on organic anion and cation transporters of the SLC22A family. Antimicrob. Agents Chemother. 60, 6558-6567. doi:10.1128/AAC.01151-16

Parvez, M. M., Shin, H. J., Jung, J. A., and Shin, J. G. (2017). Evaluation of paraaminosalicylic acid as a substrate of multiple solute carrier uptake transporters and possible drug interactions with nonsteroidal anti-inflammatory drugs in vitro. Antimicrob. Agents Chemother. 61, e02392-16. doi:10.1128/aac. 02392-16 
Parvez, M. M., Kaisar, N., Shin, H. J., Lee, Y. J., and Shin, J. G. (2018). Comprehensive substrate characterization of 22 antituberculosis drugs for multiple solute carrier (SLC) uptake transporters in vitro. Antimicrob. Agents Chemother. 62, e00512-18. doi:10.1128/AAC.00512-18

Prueksaritanont, T., Chu, X., Gibson, C., Cui, D., Yee, K. L., Ballard, J., et al. (2013). Drug-drug interaction studies: regulatory guidance and an industry perspective. AAPS J. 15, 629-645. doi:10.1208/s12248-013-9470-x

Rossato, L. G., Costa, V. M., De Pinho, P. G., Carvalho, F., De Lourdes Bastos, M., and Remião, F. (2011). Structural isomerization of synephrine influences its uptake and ensuing glutathione depletion in rat-isolated cardiomyocytes. Arch. Toxicol. 85, 929-939. doi:10.1007/s00204-010-0630-9

Salomon, J. J., Hagos, Y., Petzke, S., Kühne, A., Gausterer, J. C., Hosoya, K., et al. (2015). Beta-2 adrenergic agonists are substrates and inhibitors of human organic cation transporter 1. Mol. Pharm. 12, 2633-2641. doi:10.1021/ mp500854e

Schaeffeler, E., Hellerbrand, C., Nies, A. T., Winter, S., Kruck, S., Hofmann, U., et al. (2011). DNA methylation is associated with downregulation of the organic cation transporter OCT1 (SLC22A1) in human hepatocellular carcinoma. Genome Med. 3, 82. doi:10.1186/gm298

Sekhar, G. N., Fleckney, A. L., Boyanova, S. T., Rupawala, H., Lo, R., Wang, H., et al. (2019). Region-specific blood-brain barrier transporter changes leads to increased sensitivity to amisulpride in Alzheimer's disease. Fluids Barriers CNS. 16, 38. doi:10.1186/s12987-019-0158-1

Sekhar, G. N., Georgian, A. R., Sanderson, L., Vizcay-Barrena, G., Brown, R. C., Muresan, P., et al. (2017). Organic cation transporter 1 (OCT1) is involved in pentamidine transport at the human and mouse blood-brain barrier (BBB). PLoS One 12, e0173474. doi:10.1371/journal.pone.0173474

Shi, R., Xu, Z., Xu, X., Jin, J., Zhao, Y., Wang, T., et al. (2019). Organic cation transporter and multidrug and toxin extrusion 1 co-mediated interaction between metformin and berberine. Eur. J. Pharmaceut. Sci. 127, 282-290. doi:10.1016/j.ejps.2018.11.010

Shibata, M., Toyoshima, J., Kaneko, Y., Oda, K., and Nishimura, T. (2020). A drugdrug interaction study to evaluate the impact of peficitinib on OCT1- and MATE1-mediated transport of metformin in healthy volunteers. Eur. J. Clin. Pharmacol. 76, 1135-1141. doi:10.1007/s00228-020-02876-2

Shu, Y., Leabman, M. K., Feng, B., Mangravite, L. M., Huang, C. C., Stryke, D., et al. (2003). Evolutionary conservation predicts function of variants of the human organic cation transporter, OCT1, Proc. Natl. Acad. Sci. U.S.A. 100, 5902-5907. doi:10.1073/pnas.0730858100

Shu, Y., Sheardown, S. A., Brown, C., Owen, R. P., Zhang, S., Castro, R. A., et al. (2007). Effect of genetic variation in the organic cation transporter 1 (OCT1) on metformin action. J. Clin. Invest. 117, 1422-1431. doi:10.1172/JCI30558

Shu, Y. (2011). Research progress in the organic cation transporters. Zhong Nan Da Хие Xие Bao Yi Xue Ban. 36, 913-926. doi:10.3969/j.issn.1672-7347.2011. 10.001

Smolders, E. J., Colbers, A., De Kanter, C. T. M. M., Velthoven-Graafland, K., Wolberink, L. T., Van Ewijk-Beneken Kolmer, N., et al. (2017). Metformin and daclatasvir: absence of a pharmacokinetic-pharmacodynamic drug interaction in healthy volunteers. Br. J. Clin. Pharmacol. 83, 2225-2234. doi:10.1111/bcp.13323

Sotgiu, G., Centis, R., D’ambrosio, L., and Migliori, G. B. (2015). Tuberculosis treatment and drug regimens. Cold Spring Harb. Perspect. Med. 5, a017822. doi:10.1101/cshperspect.a017822

Stage, T. B., Lee, M. P., Hallas, J., Christensen, M. M., Brøsen, K., Christensen, K., et al. (2016). Early discontinuation of metformin in individuals treated with inhibitors of transporters of metformin. Basic Clin. Pharmacol. Toxicol. 118, 487-495. doi:10.1111/bcpt.12579

Sugawara-Yokoo, M., Urakami, Y., Koyama, H., Fujikura, K., Masuda, S., Saito, H., et al. (2000). Differential localization of organic cation transporters rOCT1 and rOCT2 in the basolateral membrane of rat kidney proximal tubules. Histochem. Cell Biol. 114, 175-180. doi:10.1007/s004180000186

Sun, W., Sanderson, P. E., and Zheng, W. (2016). Drug combination therapy increases successful drug repositioning. Drug Discov. Today. 21, 1189-1195. doi:10.1016/j.drudis.2016.05.015

Takano, H., Ito, S., Zhang, X., Ito, H., Zhang, M. R., Suzuki, H., et al. (2017). Possible role of organic cation transporters in the distribution of [11C]sulpiride, a dopamine D2 receptor antagonist. J. Pharm. Sci. 106, 2558-2565. doi:10.1016/ j.xphs.2017.05.006
Takeda, M., Khamdang, S., Narikawa, S., Kimura, H., Kobayashi, Y., Yamamoto, T., et al. (2002). Human organic anion transporters and human organic cation transporters mediate renal antiviral transport. J. Pharmacol. Exp. Ther. 300, 918-924. doi:10.1124/jpet.300.3.918

Takeuchi, T., Tanaka, Y., Iwasaki, M., Ishikura, H., Saeki, S., and Kaneko, Y. (2016). Efficacy and safety of the oral Janus kinase inhibitor peficitinib (ASP015K) monotherapy in patients with moderate to severe rheumatoid arthritis in Japan: a 12-week, randomised, double-blind, placebo-controlled phase IIb study. Ann. Rheum. Dis. 75, 1057-1064. doi:10.1136/annrheumdis-2015-208279

Taur, J. S., and Rodriguez-Proteau, R. (2008). Effects of dietary flavonoids on the transport of cimetidine via P-glycoprotein and cationic transporters in Caco-2 and LLC-PK1 cell models. Xenobiotica. 38 1536-1550. doi:10.1080/ 00498250802499467

Te Brake, L. H., Van Den Heuvel, J. J., Buaben, A. O., Van Crevel, R., Bilos, A., Russel, F. G., et al. (2016). Moxifloxacin is a potent in vitro inhibitor of OCTand MATE-mediated transport of metformin and ethambutol. Antimicrob. Agents Chemother. 60, 7105-7114. doi:10.1128/AAC.01471-16

Tu, M., Sun, S., Wang, K., Peng, X., Wang, R., Li, L., et al. (2013). Organic cation transporter 1 mediates the uptake of monocrotaline and plays an important role in its hepatotoxicity. Toxicology. 311, 225-230. doi:10.1016/j.tox.2013. 06.009

Tweedie, D., Polli, J. W., Berglund, E. G., Huang, S. M., Zhang, L., Poirier, A., et al. (2013). Transporter studies in drug development: experience to date and follow-up on decision trees from the International Transporter Consortium. Clin. Pharmacol. Ther. 94, 113-125. doi:10.1038/clpt.2013.77

Tzvetkov, M. V., Dos Santos Pereira, J. N., Meineke, I., Saadatmand, A. R., Stingl, J. C., and Brockmöller, J. (2013). Morphine is a substrate of the organic cation transporter OCT1 and polymorphisms in OCT1 gene affect morphine pharmacokinetics after codeine administration. Biochem. Pharmacol. 86, 666-678. doi:10.1016/j.bcp.2013.06.019

Tzvetkov, M. V., Vormfelde, S. V., Balen, D., Meineke, I., Schmidt, T., Sehrt, D., et al. (2009). The effects of genetic polymorphisms in the organic cation transporters OCT1, OCT2, and OCT3 on the renal clearance of metformin. Clin. Pharmacol. Ther. 86, 299-306. doi:10.1038/clpt.2009.92

Van Der Velden, M., Bilos, A., Van Den Heuvel, J. J. M. W., Rijpma, S. R., Hurkmans, E. G. E., Sauerwein, R. W., et al. (2017). Proguanil and cycloguanil are organic cation transporter and multidrug and toxin extrusion substrates. Malar. J. 16, 422. doi:10.1186/s12936-017-2062-y

Varhe, A., Olkkola, K. T., and Neuvonen, P. J. (1994). Oral triazolam is potentially hazardous to patients receiving systemic antimycotics ketoconazole or itraconazole. Clin. Pharmacol. Ther. 56, 601-607. doi:10.1038/clpt.1994.184

Vermeer, L. M., Isringhausen, C. D., Ogilvie, B. W., and Buckley, D. B. (2016). Evaluation of ketoconazole and its alternative clinical CYP3A4/5 inhibitors as inhibitors of drug transporters: the in vitro effects of ketoconazole, ritonavir, clarithromycin, and itraconazole on 13 clinically-relevant drug transporters. Drug Metab. Dispos. 44, 453-459. doi:10.1124/dmd.115.067744

Wang, J., Hughes, T. P., Kok, C. H., Saunders, V. A., Frede, A., Groot-Obbink, K., et al. (2012). Contrasting effects of diclofenac and ibuprofen on active imatinib uptake into leukaemic cells. Br. J. Cancer 106, 1772-1778. doi:10.1038/bjc. 2012.173

Wenge, B., Geyer, J., and Bönisch, H. (2011). Oxybutynin and trospium are substrates of the human organic cation transporters. Naunyn-Schmiedeberg's Arch. Pharmacol. 383, 203-208. doi:10.1007/s00210-010-0590-x

Yamazaki, T., Desai, A., Goldwater, R., Han, D., Lasseter, K. C., Howieson, C., et al. (2017). Pharmacokinetic interactions between isavuconazole and the drug transporter substrates atorvastatin, digoxin, metformin, and methotrexate in healthy subjects. Clin. Pharmacol. Drug Dev. 6, 66-75. doi: $10.1002 /$ cpdd. 280

Zamek-Gliszczynski, M. J., Hoffmaster, K. A., Tweedie, D. J., Giacomini, K. M., and Hillgren, K. M. (2012). Highlights from the international transporter Consortium second workshop. Clin. Pharmacol. Ther. 92, 553-556. doi:10. 1038/clpt.2012.126

Zhang, L., Gorset, W., Washington, C. B., Blaschke, T. F., Kroetz, D. L., and Giacomini, K. M. (2000). Interactions of HIV protease inhibitors with a human organic cation transporter in a mammalian expression system. Drug Metab. Dispos. 28, 329-334. 
Zhang, S., Lovejoy, K. S., Shima, J. E., Lagpacan, L. L., Shu, Y., Lapuk, A., et al. (2006). Organic cation transporters are determinants of oxaliplatin cytotoxicity. Cancer Res. 66, 8847-8857. doi:10.1158/0008-5472.CAN-06-0769

Zhou, M., Xia, L., and Wang, J. (2007). Metformin transport by a newly cloned proton-stimulated organic cation transporter (plasma membrane monoamine transporter) expressed in human intestine. Drug Metab. Dispos. 35, 1956-1962. doi:10.1124/dmd.107.015495

Zhu, P., Ye, Z., Guo, D., Xiong, Z., Huang, S., Guo, J., et al. (2018). Irinotecan alters the disposition of morphine via inhibition of organic cation transporter 1 (OCT1) and 2 (OCT2). Pharm. Res. (N. Y.). 35, 243. doi:10.1007/s11095-018-2526-y
Conflict of Interest: The authors declare that the research was conducted in the absence of any commercial or financial relationships that could be construed as a potential conflict of interest.

Copyright $\odot 2021$ Zhou, Zeng and Shu. This is an open-access article distributed under the terms of the Creative Commons Attribution License (CC BY). The use, distribution or reproduction in other forums is permitted, provided the original author(s) and the copyright owner(s) are credited and that the original publication in this journal is cited, in accordance with accepted academic practice. No use, distribution or reproduction is permitted which does not comply with these terms. 